\title{
Household consumption when the marriage is stable*
}

\author{
Laurens Cherchye ${ }^{\dagger} \quad$ Thomas Demuynck ${ }^{\ddagger} \quad$ Bram De Rock $^{\S}$ \\ Frederic Vermeulen
}

September, 2016

\begin{abstract}
We develop a novel framework to analyze the structural implications of the marriage market for household consumption. We define a revealed preference characterization of efficient household consumption when the marriage is stable. We characterize stable marriage with intrahousehold (consumption) transfers but without assuming transferable utility. Our revealed preference characterization generates testable conditions even with a single observation per household and heterogeneous individual preferences across households. The characterization also allows for identifying the intrahousehold decision structure (including the sharing rule) under the same minimalistic assumptions. An application to Dutch household data illustrates the usefulness of our theoretical results.
\end{abstract}

JEL Classification: C14, D11, C78.

${ }^{*}$ We thank Co-Editor Luigi Pistaferri and four anonymous referees for their insightful comments, which substantially improved our paper. We are grateful to Khushboo Surana for able research assistance. We also thank Martin Browning, Jan Eeckhout, Patrick Legros, Arthur Lewbel, Jeremy Lise, Rika Ponnet and seminar participants in Antwerp, Barcelona, Bristol, Brussels, Ca'Foscari Venice, the Chinese University of Hong Kong, Ghent, Leicester, Leuven, Louvain-la-Neuve, Munich, Namur, Oxford, Tilburg, Toulouse, University College London, ADRES 2015, ESEM 2014, RES 2015, Barcelona GSE Summer Forum 2016, and the CEREC, MEQIN and THRED Workshops for useful suggestions.

${ }^{\dagger}$ Department of Economics, University of Leuven (KU Leuven). E. Sabbelaan 53, B-8500 Kortrijk, Belgium. E-mail: laurens.cherchye@kuleuven.be. Laurens Cherchye gratefully acknowledges the European Research Council (ERC) for his Consolidator Grant 614221 and the Research Fund KU Leuven for the grant STRT1/08/004.

${ }^{\ddagger}$ ECARES, Université Libre de Bruxelles and Maastricht University. Avenue F. D. Roosevelt 50, CP 114, B-1050 Brussels, Belgium. Email: thomas.demuynck@ulb.ac.be.

${ }^{\S}$ ECARES, Université Libre de Bruxelles and Department of Economics, University of Leuven (KU Leuven). Avenue F. D. Roosevelt 50, CP 114, B-1050 Brussels, Belgium. E-mail: bderock@ulb.ac.be. Bram De Rock gratefully acknowledges FWO and BELSPO for their support.

`Department of Economics, University of Leuven (KU Leuven). Naamsestraat 69, B-3000 Leuven, Belgium. E-mail: frederic.vermeulen@kuleuven.be. Frederic Vermeulen gratefully acknowledges financial support from the Research Fund KU Leuven through the grant STRT/12/001 and from the FWO through the grant G057314N. 
Keywords: marriage market, stable matching, Pareto efficient household consumption, testable implications, sharing rule identification, preference heterogeneity.

\section{Introduction}

As soon as one recognizes that multi-person households do not behave as single "unitary" decision makers, one faces the important question on what drives the intrahousehold allocation of resources. The answer to this question is crucial if one wants to assess the impact of policy reforms on individual welfare, or if one wants to analyze poverty and inequality at the level of individuals rather than households. A useful framework to address this issue has been proposed by Chiappori $(1988,1992)$ in his seminal work on the collective model. This collective model takes as a starting point that multi-person households consist of different individuals with their own rational preferences. Observed household consumption behavior is then regarded as the outcome of an intrahousehold bargaining process that gives rise to Pareto efficient intrahousehold allocations. ${ }^{1}$

In the collective model, the resource distribution within households is governed by the sharing rule. Considerable attention has been devoted to the identification of this sharing rule on the basis of observed household consumption behavior alone. Chiappori and Ekeland (2006, 2009) provided a complete characterization of the collective model, and laid out the conditions under which the sharing rule is identified on the basis of the aggregate household consumption as a continuous function of prices and income. An alternative sharing rule identification approach, which is based on the theory of revealed preference, has been proposed by Cherchye, De Rock and Vermeulen (2011) and Cherchye, De Rock, Lewbel and Vermeulen

\footnotetext{
${ }^{1}$ The collective model has become a workhorse model in the family economics literature. It has been proven to be a viable alternative to the unitary model that is deficient when used in a context of multi-person decisionmaking. See, for example, Browning and Chiappori (1998), Cherchye and Vermeulen (2008), Cherchye, De Rock and Vermeulen $(2007,2009,2011)$ and Attanasio and Lechene (2014). At this point, we remark that it is sometimes argued that the assumption of Pareto efficiency is overly strong in a household context (see, for example, Lundberg and Pollak, 2003). As an alternative, the noncooperative model assumes Nash equilibrium allocations within the household (see, for example, Browning, Chiappori and Lechene, 2010, Lechene and Preston, 2011, and Cherchye, Demuynck and De Rock, 2011). Del Boca and Flinn (2014) recently provided an empirical analysis of cooperative versus noncooperative household behavior on the basis of observed sorting patterns on the marriage market. We see the extension of our framework towards the case of noncooperative household consumption as a possible avenue for follow-up research.
} 
(2015). Empirical applications of the two approaches have convincingly demonstrated that the sharing rule depends on variables like individual wages, prices or distribution factors. ${ }^{2}$

However, these existing approaches do not really provide a structural explanation of why intrahousehold sharing depends on wages, prices and distribution factors. Browning, Chiappori and Weiss (2014) state that "the collective model, in its fully general form, is agnostic about the decision process provided that the latter generates Pareto efficient outcomes" (p. 122). Current methods for analyzing collective household behavior define individuals' bargaining weights as "reduced form" functions of particular characteristics of marriage markets. There is no structural modeling of how these characteristics enter the decision making process. More generally, the current literature provides largely a black box treatment of how individuals come to a particular model of interaction.

In this paper, we introduce a novel framework to open this black box. It gives a structural interpretation to observed household choice behavior and the resulting intrahousehold distribution of resources. It explicitly relates within-household allocation patterns to the structure of the marriage market. More specifically, it integrates the assumption of a stable marriage market with the collective consumption model to analyze the choice behavior of households and to identify the sharing rule. ${ }^{3}$

The basic idea is that there are economic gains from marriage through the consumption of public goods, which generates economies of scale. Firstly, we take it that these economic gains drive marriage decisions, in the sense that they potentially allow an individual to be better off in a couple than as a single. A stable marriage then implies that this potential is realized. Secondly, stability requires that the within-marriage consumption allocation with the current partner is at least as good as the allocation that would be obtained with any other partner.

\footnotetext{
${ }^{2}$ Distribution factors have an impact on the household decision processes through individuals' bargaining weights, but have no direct effect on individual preferences or budget constraints. See, for example, Browning, Bourguignon, Chiappori and Lechene (1994), Chiappori, Fortin and Lacroix (2002), Blundell, Chiappori and Meghir (2005), Lewbel and Pendakur (2008), Bourguignon, Browning and Chiappori (2009), Couprie, Peluso and Trannoy (2010), Lise and Seitz (2011), Bargain and Donni (2012), Cherchye, De Rock and Vermeulen (2012), Browning, Chiappori and Lewbel (2013), and Dunbar, Lewbel and Pendakur (2013) for various applications of the collective consumption model that make use of the sharing rule concept.

${ }^{3}$ See the seminal papers of Gale and Shapley (1962), Shapley and Shubik (1972) and Becker (1973) for early contributions on the concept of stable marriage. Browning, Chiappori and Weiss (2014, Chapters 7 and 8 ) provide a recent account of the literature on stable matching on the marriage market. Chiappori and Salanié (2015) review the literature on the econometrics of matching models.
} 
We apply a genuine revealed preference argument to extract preference information from the observed marriage behavior: since married individuals have revealed their preference for living with their current partner over living alone or with a different partner, they must prefer their consumption allocation within marriage above any possible allocation outside marriage. As the within-marriage allocation is defined by the intrahousehold sharing rule, this effectively allows us to recover within-household sharing patterns from information on the individuals' outsidemarriage consumption possibilities. That is, we use data on individual's budget conditions (i.e., prices and incomes) that apply as single or with other potential partners to learn about the (unobserved) resource distribution with the current partner.

As we will show below, by formalizing this intuitive reasoning we obtain testable implications for household consumption patterns that allow us to check whether observed choice behavior is consistent with the collective model in the context of a stable marriage market. If these restrictions cannot be rejected, then they usefully allow for informative sharing rule identification. Specifically, we will define bounds on individual resource shares that are consistent with the collective consumption model and our assumption of marital stability, which effectively "set" identifies the sharing rule. An interesting feature of our testable conditions is that they can be implemented by means of standard linear programming techniques. At this point, we emphasize that our framework can actually also be used to recover other fundamentals of the intrahousehold interaction process (such as individual preferences), in addition to the sharing rule. However, to focus our discussion, and given its prominent position in the literature on collective consumption models, our central focus here will be on identifying intrahousehold resource shares.

In its purest form, our theory assumes that individuals marry with each other only because of economic gains from marriage and that preferences over consumption are not match-specific. As such, our basic model does not include match quality, which is an important concept in the matching literature (see Browning, Chiappori and Weiss, 2014). Clearly, as soon as one wants to identify the sharing rule on the basis of aggregate choice behavior alone, one has to make assumptions of this nature. Still, we will also demonstrate how one can allow for deviations from our conditions of marriage stability in practical applications. To this end, we 
will introduce "stability indices", which represent income losses associated with exiting the current marriage. As we will explain, one may interpret these stability indices as measuring unobserved match quality in monetary terms, so that this provides an operational method to account for match quality in empirical analyses.

To conclude this introduction, we emphasize three important specific aspects of our framework. First, because we account for consumption sharing within the household, we consider intrahousehold transfers by construction. However, unlike the usual practice in the literature on characterizing stable marriage, we do so without making the assumption that individual utilities are transferable. Indeed, it is well-documented that such transferable utilities imply substantial structure for the individual preferences. ${ }^{4,5}$ Second, to address our central research question, we develop a characterization of household consumption under stable marriage that follows the revealed preference tradition of Samuelson $(1938,1948)$, Houthakker (1950), Afriat (1967), Diewert (1973) and Varian (1982). An attractive feature of this revealed preference characterization is that it is intrinsically nonparametric: its empirical implementation does not require an (explicit or implicit) functional specification of individual utilities. Third, even though we impose these minimalistic priors, our methodology generates strong testable implications for household consumption patterns. In particular, these implications have empirical bite even in the limiting case with a cross-section containing (only) a single observation per household and when accounting for any (unobservable) heterogeneity across households (in terms of individual preferences and within-household decision processes). This stands in sharp contrast with the existing approaches that we mentioned above, which typically require multiple observations for one and the same household (e.g., a household demand function) and/or

\footnotetext{
${ }^{4}$ Chiappori and Gugl (2015) give a complete characterization of preferences with transferable utility in a differentiable framework. They show that a necessary condition for transferable utility is that household members behave as a single individual. Given the overwhelming evidence against the unitary model that we cited above, it is clear that this is an overly strong assumption. See also Chiappori (2010) and Cherchye, Demuynck and De Rock (2014) for related discussions.

${ }^{5}$ Choo and Siow (2006), Chiappori, Oreffice and Quintana-Domeque (2012), Chiappori, Iyigun, Lafortune and Weiss (2013), Echenique, Lee, Shum and Yenmez (2013), Jacquemet and Robin (2013), Dupuy and Galichon (2014) and Galichon and Salanié (2014) analyze stable marriage under the assumption that individual utilities are transferable. More similar to our set-up, Chiappori and Reny (2006), Legros and Newman (2007), Choo and Seitz (2013), Browning, Chiappori and Weiss (2014, Chapter 7.3) and Galichon, Kominers and Weber (2014) also consider settings with transfers but no transferable utility. In this respect, a specific distinguishing feature of our study is that it develops an empirical revealed preference methodology that is intrinsically nonparametric.
} 
preference homogeneity across households.

The remainder of this study unfolds as follows. In Section 2, we introduce our notation and formally define our concept of stable marriage. Section 3 then provides the corresponding revealed preference characterization. Here, we also show that this characterization implies testable implications that are easy to operationalize for observational household consumption data. In addition, we will indicate how these testable implications can be used to address sharing rule (set) identification. Section 4 presents an illustrative application to Dutch household consumption data, which demonstrates the empirical usefulness of our revealed preference methodology. Section 5 concludes.

\section{Stable marriage}

We consider an empirical analyst who observes a set of matched (married) households with (aggregate) consumption bundles that consist of publicly and privately consumed quantities. As emphasized above, a crucial point of our basic model is that individuals marry with each other because of economic gains coming from public consumption (which generates economies of scale). We assume that households make consumption decisions that are collectively rational, i.e., intrahousehold allocations are Pareto efficient. Next, we also assume that consumption patterns are such that marriages are stable, i.e., no individual wants to exit marriage. Formally, a marriage is stable if it is "individually rational" and has "no blocking pairs". Individual rationality means that no individual prefers becoming single over staying married. Similarly, no blocking pairs means that there are no two individuals who want to exit their current marriages to remarry each other.

In what follows, we will formalize these intuitive concepts, to subsequently define a "stable matching allocation" as one that meets Pareto efficiency, individual rationality and no blocking pairs. Two preliminary remarks are in order. First, individual preferences over consumption are assumed not to be match-specific, which implies that there is no match quality. At the end of Section 3, we indicate how we can account for match quality in practical applications. Second, we assume that all individuals are matched in the theory that we present in this and 
the following section. However, in our empirical application in Section 4 we will use a data set that includes singles, and we account for the possibility that a married individual may consider remarrying a single of the other gender. ${ }^{6}$ Actually, if we do not consider stability conditions for singles' behavior, it is relatively straightforward to formally add this possibility to our theoretical set-up. However, unless there is a shortage on one side of the marriage market, rationalizing the behavior of singles requires an explicit model for frictions on the marriage market and/or marriage costs. To focus our discussion, we abstract from such extensions in the current study.

\subsection{Notation}

We consider households that consist of males $m$ and females $w$. In particular, we start from a finite set of men $M$ and a finite set of women $W$. The marriage market is characterized by a matching function $\sigma: M \cup W \rightarrow M \cup W \cup\{\emptyset\}$. This function satisfies, for all $m \in M$ and $w \in W$,

$$
\begin{aligned}
& \sigma(m) \in W \cup\{\emptyset\}, \\
& \sigma(w) \in M \cup\{\emptyset\}, \\
& \sigma(m)=w \in W \text { if and only if } \sigma(w)=m \in M
\end{aligned}
$$

In words, the function $\sigma$ assigns to every man or woman either a partner of the other gender (i.e. $\sigma(m)=w$ and $\sigma(w)=m$ ) or nobody (i.e. $\sigma(m)=\emptyset$ and $\sigma(w)=\emptyset$ ), which means that the man/woman remains single. If $\sigma(m)=w$, we say that man $m$ is matched to woman $w$ and vice versa, i.e. $w$ and $m$ form a married pair. If all individuals are matched, we have that $\sigma(m) \neq \emptyset$ and $\sigma(w) \neq \emptyset$ for any $m$ and $w$ (which requires $|M|=|W|$ ).

Married couples make consumption decisions. In particular, we assume that households consume a set of commodities, which may include the spouses' leisure (as in our application

\footnotetext{
${ }^{6}$ We remark that, by using singles as potential remarriage partners for married individuals, we can account for the impact of sex ratios on intrahousehold sharing patterns when analyzing household consumption behavior in a stable marriage market. See, for example, Chiappori, Fortin and Lacroix (2002) and Amuedo-Dorantes and Grossbard (2007) for empirical analyses showing the impact of sex ratios on the allocation of time and resources within households.
} 
in Section 4). The set of commodities consists of both private and public goods. We denote by $q \in \mathbb{R}_{+}^{n}$ a (column) vector of $n$ private goods and by $Q \in \mathbb{R}_{+}^{k}$ a (column) vector of $k$ (intrahousehold) public goods. For any married pair $(m, \sigma(m)),\left(q_{m, \sigma(m)}, Q_{m, \sigma(m)}\right)$ represents the observed aggregate consumption bundle of private and public goods.

Consumption decisions are made under budget constraints, which are defined by prices and incomes for any pair $(m, w)$. We consider a (row) price vector $p_{m, w} \in \mathbb{R}_{++}^{n}$ for the private goods and a (row) price vector $P_{m, w} \in \mathbb{R}_{++}^{k}$ for the public goods. For leisure, prices equal the spouses' wages. The vectors $p_{m, \emptyset}$ and $P_{m, \emptyset}$ contain the private good and public good prices for a single man and, analogously, $p_{\emptyset, w}$ and $P_{\emptyset, w}$ contain the prices for a single woman. ${ }^{7}$ Next, $y_{m, w} \in \mathbb{R}_{++}$ gives the potential income of the pair $(m, w)$. Similarly, $y_{m, \emptyset}$ and $y_{\emptyset, w}$ are the incomes of a single man $m$ and woman $w$. If consumption includes leisure, then these incomes are full incomes. We assume that the empirical analyst observes prices and incomes for (unobserved) pairs that are not matched and for (unobserved) singles. However, we only observe the actual consumption quantities for the matched pairs. We will return to these observational issues in Section 3, when we explain the type of data sets that we consider, and in Section 4, when we present our empirical application.

For a given pair $(m, w)$, the private consumption bundle $q_{m, w}$ is shared between the male and the female. This obtains the male quantities $q_{m, w}^{m} \in \mathbb{R}_{+}^{n}$ and female quantities $q_{m, w}^{w} \in \mathbb{R}_{+}^{n}$ that satisfy the adding up condition $q_{m, w}^{m}+q_{m, w}^{w}=q_{m, w}$. For a bundle $\left(q_{m, w}, Q_{m, w}\right)$, this defines the household allocation $\left(q_{m, w}^{m}, q_{m, w}^{w}, Q_{m, w}\right)$. Then, for given $\sigma$ the matching allocation $S=\left\{\left(q_{m, \sigma(m)}^{m}, q_{m, \sigma(m)}^{\sigma(m)}, Q_{m, \sigma(m)}\right)\right\}_{m \in M}$ is the collection of household allocations defined over all matched pairs. ${ }^{8}$

Finally, every man $m$ is endowed with a non-negative, increasing, continuous and concave utility function $u^{m}: \mathbb{R}_{+}^{n+k} \rightarrow \mathbb{R}_{+}$, which associates a certain level of utility with every bundle $\left(q^{m}, Q\right)$. Analogously, each woman $w$ has a non-negative, increasing, continuous and concave

\footnotetext{
${ }^{7}$ Admittedly, for singles the distinction between private and public consumption becomes artificial. Still, we choose to maintain the distinction here to ease our exposition and to avoid an overload of notation.

${ }^{8}$ In the current paper, we focus on a collective model with the (private or public) nature of the goods specified a priori, and no externalities for the private goods. In this respect, we remark that we can easily account for (positive) externalities by formally treating private goods with externalities as public goods. Next, it is less straightforward to define the nature of the goods endogenously. One possibility to address this issue is to integrate the framework of Browning, Chiappori and Lewbel (2013) in our set-up.
} 
utility function $u^{w}: \mathbb{R}_{+}^{n+k} \rightarrow \mathbb{R}_{+}$. We assume that $u^{m}\left(q^{m}, Q\right)$ and $u^{w}\left(q^{w}, Q\right)$ are strictly increasing in, respectively, $q^{m}$ and $q^{w}$. Next, as a regularity condition, we use that $u^{m}(0, Q)=$ $u^{w}(0, Q)=0$ for any level of public goods $Q$. In words, both men and women must consume at least some private goods to have positive utility (for example, if food is a private good, individuals need to consume at least some food to experience positive utility). Finally, we assume that males and females have complete information about each others' preferences. $^{9}$

\subsection{Stable matching allocation}

A matching allocation is stable if it is Pareto efficient, individually rational and has no blocking pairs. First, Pareto efficiency requires that no Pareto improvement is possible for any matched pair $(m, \sigma(m))$. That is, for the given prices $p_{m, \sigma(m)}$ and $P_{m, \sigma(m)}$ and income $y_{m, \sigma(m)}$, there does not exist another intrahousehold allocation of the consumption goods that makes at least one member strictly better off without making the other member worse off. As explained before, Pareto efficiency means that observed consumption behavior is consistent with the collective model of household consumption.

Definition 1 For a given matching $\sigma$, the matching allocation $S=\left\{\left(q_{m, \sigma(m)}^{m}, q_{m, \sigma(m)}^{\sigma(m)}, Q_{m, \sigma(m)}\right)\right\}_{m \in M}$ is Pareto efficient if, for all $m \in M$, there exists no feasible allocation $\left(q^{m}, q^{w}, Q\right)$, i.e.,

$$
p_{m, \sigma(m)}\left(q^{m}+q^{w}\right)+P_{m, \sigma(m)} Q \leq y_{m, \sigma(m)}
$$

such that

$$
\begin{aligned}
& u^{m}\left(q^{m}, Q\right) \geq u^{m}\left(q_{m, \sigma(m)}^{m}, Q_{m, \sigma(m)}\right), \\
& u^{\sigma(m)}\left(q^{w}, Q\right) \geq u^{\sigma(m)}\left(q_{m, \sigma(m)}^{\sigma(m)}, Q_{m, \sigma(m)}\right),
\end{aligned}
$$

\footnotetext{
${ }^{9}$ Incomplete preference information may result in deviations from the "exact" stability conditions that we formulate in Section 3. In what follows, we show how we can allow for deviations from our conditions of marriage stability by using "stability indices". We will mainly focus on the interpretation of these indices in terms of unobserved match quality, but they may actually also be regarded as capturing mismatch due to incomplete preference information. In this respect, see also Liu, Malaith, Postlewaith and Samuelson (2014) for a recent discussion on stable matching with incomplete information, and its relation to stable matching with complete information.
} 
with at least one strict inequality.

Next, individual rationality requires that no individual is better off as a single than under the matching $\sigma$. To define this concept formally, we let $U_{m, \emptyset}^{m}\left(U_{\emptyset, w}^{w}\right)$ represent the maximum utility level that man $m$ (woman $w$ ) could obtain by staying single, when faced with the prices $p_{m, \emptyset}$ and $P_{m, \emptyset}$, and income $y_{m, \emptyset}\left(p_{\emptyset, w}\right.$ and $P_{\emptyset, w}$, and $\left.y_{\emptyset, w}\right)$, i.e.,

$$
\begin{aligned}
& U_{m, \emptyset}^{m}=\max _{q^{m}, Q} u^{m}\left(q^{m}, Q\right) \text { s.t. } p_{m, \emptyset} q^{m}+P_{m, \emptyset} Q \leq y_{m, \emptyset}, \\
& U_{\emptyset, w}^{w}=\max _{q^{w}, Q} u^{w}\left(q^{w}, Q\right) \text { s.t. } p_{\emptyset, w} q^{w}+P_{\emptyset, w} Q \leq y_{\emptyset, w} .
\end{aligned}
$$

Then, we have the following definition.

Definition 2 For a given matching $\sigma$, the matching allocation $S=\left\{\left(q_{m, \sigma(m)}^{m}, q_{m, \sigma(m)}^{\sigma(m)}, Q_{m, \sigma(m)}\right)\right\}_{m \in M}$ is individually rational if, for all $m \in M$ and $w \in W$, we have

$$
\begin{aligned}
& u^{m}\left(q_{m, \sigma(m)}^{m}, Q_{m, \sigma(m)}\right) \geq U_{m, \emptyset}^{m}, \\
& u^{w}\left(q_{\sigma(w), w}^{w}, Q_{\sigma(w), w}\right) \geq U_{\emptyset, w}^{w} .
\end{aligned}
$$

Finally, we say that an (unmatched) pair $(m, w)$ is a blocking pair if the associated prices $p_{m, w}, P_{m, w}$ and income $y_{m, w}$ admit an allocation such that, when compared to the matching $\sigma$, at least one member of the unmatched pair is better off while the other member is not worse off. A stable matching requires that no such blocking pairs exist. To formalize this idea, we consider, for any man $m$ and woman $w$,

$$
\begin{aligned}
\psi_{m, w}\left(\bar{u}^{w}\right)=\max _{q_{m, w}^{m}, q_{m, w}^{w}, Q_{m, w}} u^{m}\left(q_{m, w}^{m}, Q_{m, w}\right) \\
\text { s.t. } p_{m, w}\left(q_{m, w}^{m}+q_{m, w}^{w}\right)+P_{m, w} Q_{m, w} \leq y_{m, w}, \\
u^{w}\left(q_{m, w}^{w}, Q_{m, w}\right) \geq \bar{u}^{w} .
\end{aligned}
$$

In words, $\psi_{m, w}\left(\bar{u}^{w}\right)$ gives the maximal utility that the man $m$ can obtain when he is married to woman $w$, under the condition that $w$ 's utility equals at least $\bar{u}^{w}$. Let $\bar{U}_{m, w}^{m}$ and 
$\bar{U}_{m, w}^{w}$ represent the maximum attainable utility of the male $m$ and female $w$ in the couple $(m, w)$. Then, if we restrict $\bar{u}^{w} \in\left[0, \bar{U}_{m, w}^{w}\right]$, the function $\psi_{m, w}:\left[0, \bar{U}_{m, w}^{w}\right] \rightarrow\left[0, \bar{U}_{m, w}^{m}\right]$ traces out the Pareto frontier of the couple $(m, w)$. Using this, we get the following definition of our no blocking pairs requirement.

Definition 3 For a given matching $\sigma$, the matching allocation $S=\left\{\left(q_{m, \sigma(m)}^{m}, q_{m, \sigma(m)}^{\sigma(m)}, Q_{m, \sigma(m)}\right)\right\}_{m \in M}$ has no blocking pairs if, for all $m \in M$ and $w \in W$ with $w \neq \sigma(m)$, there exist no utility levels $U_{m, w}^{m}$ and $U_{m, w}^{w}$ such that

$$
\begin{aligned}
& U_{m, w}^{m}=\psi_{m, w}\left(U_{m, w}^{w}\right) \\
& U_{m, w}^{m} \geq u^{m}\left(q_{m, \sigma(m)}^{m}, Q_{m, \sigma(m)}\right), \\
& U_{m, w}^{w} \geq u^{w}\left(q_{\sigma(w), w}^{w}, Q_{\sigma(w), w}\right)
\end{aligned}
$$

with at least one strict inequality.

We can now define our concept of a stable matching allocation. In Appendix B, we show that such a stable allocation always exists under our set of assumptions. ${ }^{10}$

Definition 4 For a given matching $\sigma$, a matching allocation $S=\left\{\left(q_{m, \sigma(m)}^{m}, q_{m, \sigma(m)}^{\sigma(m)}, Q_{m, \sigma(m)}\right)\right\}_{m \in M}$ is stable if it is Pareto optimal, individually rational and has no blocking pair.

\section{Testable implications and identification}

In the Introduction, we explained the basic intuition behind our revealed preference argument to recover information on intrahousehold decision processes from observed marriage allocations. To formalize this reasoning, we begin by defining the type of data that we consider. We will say that a data set is rationalizable by a stable matching if it allows us to specify a

\footnotetext{
${ }^{10}$ As we explain in Appendix B, existence follows from a general result of Alkan and Gale (1990). We remark that this existence result does not necessarily imply a unique stable marriage matching. See, for example, Eeckhout (2000), Clark (2006) and Legros and Newman (2010) for conditions that guarantee uniqueness in a non-transferable utility setting that is similar to ours. Importantly, however, non-uniqueness does not interfere with the validity (and, thus, applicability) of the testable implications and (set) identification results that we derive below.
} 
matching allocation that is stable (in the sense of Definition 4). Then, we will state the revealed preference conditions that a data set needs to satisfy to be rationalizable by a stable matching. These testable implications are linear in unknowns and therefore easy to apply in practice. Moreover, we can show that they provide a useful basis to informatively (set) identify household sharing rules. In their pure form, our revealed preference conditions are "sharp": either a data set satisfies the conditions or it does not. We conclude this section by introducing the concept of "stability indices", which allow us to quantify deviations from "exact" rationalizability in terms of these sharp conditions. These stability indices can be interpreted as representing divorce costs that are associated with unobserved aspects of the matching process on the marriage market, such as match quality.

\subsection{Rationalizability}

For a given set of males $M$ and females $W$ (with $|M|=|W|$ ), we assume a data set $\mathcal{D}$ that contains the following information:

- the matching function $\sigma$,

- the consumption bundles $\left(q_{m, \sigma(m)}, Q_{m, \sigma(m)}\right)$ of all matched couples $(m, \sigma(m))$, with $m \in$ $M$

- the prices $p_{m, w}, P_{m, w}$ for all $m \in M \cup\{\emptyset\}$ and $w \in W \cup\{\emptyset\}$,

- the incomes $y_{m, w}$ for all $m \in M \cup\{\emptyset\}$ and $w \in W \cup\{\emptyset\}$.

Obviously, the empirical analyst needs to observe who matches whom (i.e., the function $\sigma$ ) to check stability of marriages. Next, we observe the (aggregate) consumption bundles $q_{m, \sigma(m)}$ and $Q_{m, \sigma(m)}$ only for pairs $(m, \sigma(m))$ that are effectively matched. By contrast, we do not observe any consumption if there is no match (i.e., a pair $(m, w)$ with $w \neq \sigma(m))$. In that case, the vectors $q_{w, m}$ and $Q_{w, m}$ represent possible consumption outcomes of $(w, m)$ if the pair had been matched, and $q_{w, m}^{w}$ and $q_{w, m}^{m}$ give the corresponding private consumption shares. The underlying idea is that individuals anticipate this consumption when evaluating alternative possible matches. 
Finally, we assume that the empirical analyst can reconstruct the budget conditions (i.e. prices $p_{m, w}, P_{m, w}$ and income $\left.y_{m, w}\right)$ for any $m \in M \cup \emptyset$ and $w \in W \cup \emptyset$, which also includes unobserved decision situations pertaining to unmatched pairs and single status. As a specific example, let us take the labor supply setting that we consider in our empirical application, in which couples have to choose a leisure-consumption bundle. Then, the price vectors $p_{w, m}$ and $P_{w, m}$ contain exogenously defined individual wages, and the incomes $y_{w, m}$ stand for the corresponding full incomes. In Section 4, we will discuss how we can specify these counterfactual prices and incomes in empirical applications.

Referring to Definition 4 , we can now state our condition for a data set $\mathcal{D}$ to be rationalizable.

Definition 5 The data set $\mathcal{D}$ is rationalizable by a stable matching if, for any $m \in M$ and $w \in W$, there exist utility functions $u^{m}$ and $u^{w}$ and individual quantities $q_{m, \sigma(m)}^{m}, q_{m, \sigma(m)}^{w} \in \mathbb{R}_{+}^{n}$, with

$$
q_{m, \sigma(m)}^{m}+q_{m, \sigma(m)}^{w}=q_{m, \sigma(m)},
$$

such that the matching allocation $\left\{\left(q_{m, \sigma(m)}^{m}, q_{m, \sigma(m)}^{\sigma(m)}, Q_{m, \sigma(m)}\right)\right\}_{m \in M}$ is stable.

At this point, it is useful to emphasize the minimalistic nature of our assumptions. Specifically, our rationalizability criterion requires only a single consumption observation per married pair. In addition, we account for heterogeneous preferences for all individuals (females and males) that are observed. A main conclusion of this study will be that it is possible to conduct an informative empirical analysis of stable marriages even under these minimalistic priors.

In this respect, we also recall that our concept of a stable matching allocation actually requires both Pareto efficient (or collectively rational) household consumption decisions and stable marriage matching (i.e., individual rationality and no blocking pairs). Notably, Pareto efficiency alone generates no testable implications for observed consumption if we can use only a single observation per household. ${ }^{11}$ Therefore, the empirical bite of our methodology stems essentially from the assumption of stable marriages. Because our central focus is precisely

\footnotetext{
${ }^{11}$ See Cherchye, De Rock and Vermeulen (2007) for a detailed analysis of the minimal data requirements (including the number of observations) that are needed for Pareto efficiency (or collective rationality) to generate testable implications.
} 
on the testable implications of this stability assumption, this also directly motivates us concentrating on data sets with only a single consumption observation per household. However, we want to point out that it is actually fairly easy to extend our framework to settings with multiple household-specific observations (albeit at the cost of notational complexity).

\subsection{Revealed preference conditions}

We next provide a revealed preference characterization of a data set $\mathcal{D}$ that is rationalizable in the sense of Definition 5. As indicated in the Introduction, such a revealed preference characterization is intrinsically nonparametric. It does not imply an explicit reference to individual utility functions, and so its verification does not need a specific parametric/functional structure for these utilities. It is directly expressed in terms of the information that is contained by the actual data set $\mathcal{D}$; no additional (possibly confounding) structure is to be imposed.

We focus on revealed preference conditions for rationalizability that are linear in unknowns (i.e., individual quantities and personalized prices), which is very convenient from a practical point of view. More specifically, the testable conditions are easily operationalized by standard linear programming techniques. Moreover, the linear conditions have an intuitive interpretation in terms of the stability criteria that we outlined in the previous section. In addition, as we will indicate, they provide a useful basis for set identifying the decision structure (including the sharing rule) underlying household consumption behavior if this behavior is found consistent with stable marriage. Importantly, the conditions do have sufficient empirical bite for an informative empirical analysis, which we will show in Section 4.

Our linear conditions are summarized in the following Proposition 1. We provide a detailed explanation of the different conditions directly after the result.

Proposition 1 If the data set $\mathcal{D}$ is rationalizable by a stable matching, then there exist

a. for each matched pair $m \in M$ and $\sigma(m) \in W$, individual quantities $q_{m, \sigma(m)}^{m}, q_{m, \sigma(m)}^{\sigma(m)} \in \mathbb{R}_{+}^{n}$ that satisfy

$$
q_{m, \sigma(m)}^{m}+q_{m, \sigma(m)}^{\sigma(m)}=q_{m, \sigma(m)}
$$

which define a matching allocation $\left\{q_{m, \sigma(m)}^{m}, q_{m, \sigma(m)}^{\sigma(m)}, Q_{m, \sigma(m)}\right\}_{m \in M}$, 
b. for each pair $(m, w)(m \in M, w \in W)$, personalized prices $P_{m, w}^{m}, P_{m, w}^{w} \in \mathbb{R}_{++}^{k}$ that satisfy

$$
P_{m, w}^{m}+P_{m, w}^{w}=P_{m, w}
$$

that simultaneously meet the following constraints:

i. individual rationality restrictions for all males $m \in M$ and females $w \in W$, i.e.,

$$
\begin{aligned}
& y_{m, \emptyset} \leq p_{m, \emptyset} q_{m, \sigma(m)}^{m}+P_{m, \emptyset} Q_{m, \sigma(m)} \\
& y_{\emptyset, w} \leq p_{\emptyset, w} q_{\sigma(w), w}^{w}+P_{\emptyset, w} Q_{\sigma(w), w} .
\end{aligned}
$$

ii. no blocking pair restrictions for all $m \in M$ and $w \in W$, i.e.,

$$
y_{m, w} \leq\left(p_{m, w} q_{m, \sigma(m)}^{m}+P_{m, w}^{m} Q_{m, \sigma(m)}\right)+\left(p_{m, w} q_{\sigma(w), w}^{w}+P_{m, w}^{w} Q_{\sigma(w), w}\right) .
$$

An attractive feature of the conditions in Proposition 1 is that we can give them a specific "revealed preference" interpretation. ${ }^{12}$ The adding up constraint in (a) specifies feasibility restrictions on the unknown quantities. In particular, the constraint pertains to individual quantities for matched pairs $(m, \sigma(m))$. Next, condition (b) defines a formally similar feasibility constraint on the personalized prices $P_{m, w}^{m}$ and $P_{m, w}^{w}$ (for any matched or unmatched pair). Intuitively, these personalized prices represent the willingness-to-pay of individual members for the public consumption. Because they must add up to the actual prices $P_{m, w}$, they can be interpreted as Lindahl prices that correspond to a Pareto optimal provision of public goods.

Next, the rationalizability restrictions (i) and (ii) bear an intuitive meaning in terms of the stability conditions that we defined in Section 2. First, condition (i) requires, for each individual male and female, that incomes and prices under single status (i.e. $y_{m, \emptyset}, p_{m, \emptyset}, P_{m, \emptyset}$

\footnotetext{
${ }^{12}$ In this respect, it is also interesting to observe that the linear conditions in Proposition 1 bear some formal similarity to the ones derived by Browning, Chiappori and Weiss (2014, Chapter 7.2) for the model of Shapley and Shubik (1972) and Becker (1973). However, a crucial difference is that Browning, Chiappori and Weiss's conditions assume that individual utilities are transferable, whereas our conditions apply to more general utility structures.
} 
for male $m$ and $y_{\emptyset, w}, p_{\emptyset, w}, P_{\emptyset, w}$ for female $\left.w\right)$ do not allow buying a bundle that is strictly more expensive than the one consumed under the current marriage (i.e. $\left(q_{m, \sigma(m)}^{m}, Q_{m, \sigma(m)}\right)$ for male $m$ and $\left(q_{\sigma(w), w}^{w}, Q_{\sigma(w), w}\right)$ for female $\left.w\right)$. Indeed, if these conditions are not met, then at least one man or woman is better off (i.e., can attain a strictly better bundle) as a single, which means that the marriage allocation is not stable. This is basically a direct application of the Weak Axiom of Revealed Preference (WARP). In a similar vein, the right hand side of the inequality in condition (ii) gives the sum value of the bundles within marriage for male $m$ (i.e. $\left.p_{m, w} q_{m, \sigma(m)}^{m}+P_{m, w}^{m} Q_{m, \sigma(m)}\right)$ and female $w$ (i.e. $p_{m, w} q_{\sigma(w), w}^{w}+P_{m, w}^{w} Q_{\sigma(w), w}$ ), evaluated at the prices that pertain to the pair $(w, m)$ (and using personalized prices to evaluate the public quantities). Condition (ii) then requires that the pair's income $y_{m, w}$ must not exceed this sum value. Intuitively, if this condition is not met, then man $m$ and woman $w$ can allocate their income so that both of them are better off (with at least one strictly better off) than with their current matches $\sigma(m)$ and $\sigma(w)$, which makes $(w, m)$ a blocking pair.

Interestingly, for a data set that satisfies the rationalizability conditions, Proposition 1 also implies an operational way to identify the intrahousehold decision structure that underlies the rationalizable consumption behavior. It allows for recovering individual quantities and personalized prices that represent the observed behavior in terms of a stable matching. Specifically, it defines feasible sets of these quantities and prices as (non-empty) feasible sets characterized by the linear constraints in Proposition 1, which effectively set identifies these unobservables (under the maintained assumption of a stable matching).

Importantly, our linear conditions also allow for recovering the sharing rule that corresponds to rationalizable household consumption. In the collective model, this sharing rule defines the individual incomes that are allocated to the male $m$ and female $w$. For a matched pair $(m, \sigma(w))$, we can define the male income share $y_{m, \sigma(m)}^{m}$ and female income share $y_{m, \sigma(m)}^{\sigma(m)}$ as

$$
\begin{aligned}
& y_{m, \sigma(m)}^{m}=p_{m, \sigma(m)} q_{m, \sigma(m)}^{m}+P_{m, \sigma(m)}^{m} Q_{m, \sigma(m)} \\
& y_{m, \sigma(m)}^{\sigma(m)}=p_{m, \sigma(m)} q_{m, \sigma(m)}^{\sigma(m)}+P_{m, \sigma(m)}^{\sigma(m)} Q_{m, \sigma(m)}
\end{aligned}
$$

where we use the personalized (Lindahl) prices to evaluate the public quantities. We remark 
that $y_{m, \sigma(m)}^{m}+y_{m, \sigma(m)}^{\sigma(m)}=y_{m, \sigma(m)}$ by construction, i.e., every share exhaustively assigns a part of the total household expenditures to each individual member.

Similar to before, we can set identify the individual income shares through linear programming. In particular, we obtain upper/lower bounds on these shares by maximizing/minimizing the linear functions (4) and (5) subject to the linear rationalizability restrictions in Proposition 1. As we emphasized before, this obtains sharing rule identification even with only a single observation per household and heterogeneous individual preferences across households. This is in stark contrast with the existing identification approaches, which assume either observability of household demand as a function of prices and income (see, for example, Chiappori, 1988, 1992, Chiappori and Ekeland, 2009, and Cherchye, De Rock, Lewbel and Vermeulen, 2015) or observability of a time series of household consumption choices (see, for example, Cherchye, De Rock and Vermeulen, 2011).

Finally, we remark that the conditions in Proposition 1 are, in general, only necessary but not sufficient for rationalizability. That is, we can conclude that a data set $\mathcal{D}$ is not rationalizable if it does not meet the conditions, but there may well exist data sets that pass these (linear) conditions but are not rationalizable in terms of Definition 5. In Appendix A, we also provide a revealed preference characterization of rationalizable behavior that is both necessary and sufficient. This characterization is nonlinear in unknowns, which makes it substantially more difficult to use in practice. ${ }^{13}$

At this point, we emphasize that our focus on the computationally and empirically attractive necessary conditions does not make our approach less interesting. Our main interest is in recovering intrahousehold decision processes from observed household behavior. From this perspective, in what follows we will maintain marriage stability as an identifying assumption, rather than treating it as an assumption that is subject to empirical testing per se (which effectively would recommend the use of testable conditions that are both necessary and sufficient). Moreover, as the empirical application in the next section will illustrate, our approach

\footnotetext{
${ }^{13}$ For example, nonlinear programming problems (with nonlinear restrictions) become computationally burdensome even for moderate sized problems. Moreover, nonlinear optimization problems do not always yield an optimal solution: most algorithms search for local optima, which need not be globally optimal (unless some additional concavity assumptions hold true). Generally, finding a global optimum requires a fine grid search over the set of initial values.
} 
does generate bounds on the sharing rule that are informatively tight. For example, they allow us to draw strong and robust conclusions about how the sharing rule varies with the spouses' wages and households' full incomes. Finally, it is quite common in empirical revealed preference analysis to focus on necessary (WARP-based) implications of rationality when analyzing household consumption behavior. See, for example, Blundell et al. (2008, 2015) and Hoderlein and Stoye (2014) for unitary household analysis, and Cherchye, De Rock, Lewbel and Vermeulen (2015) for collective household analysis.

\subsection{Divorce costs and unobserved match quality}

Our sharing rule identification method rests on the important assumption that male and female preferences of a matched couple only depend on the respective individual consumption bundles $\left(q_{m, \sigma(m)}^{m}, Q_{m, \sigma(m)}\right)$ and $\left(q_{m, \sigma(m)}^{\sigma(m)}, Q_{m, \sigma(m)}\right)$. This implies that we assume that an individual's preferences do not depend on the partner's identity. As such, in its purest form, there is no room for love or, more generally, match-specific preferences. Obviously, an assumption like this one is needed to give empirical content to the concept of marriage stability. For example, if we allowed for general match-specific preferences, then any match could be rationalized by a sufficiently high match-specific utility gain. ${ }^{14}$

Still, it is clear that marriage formation and dissolution is not only driven by economic gains from marriage. And, thus, we may reasonably expect that the above stability conditions will not be satisfied by all matched couples in real-world data sets. To account for such deviations from our (sharp) stability requirements, we introduce the concept of "stability indices", which represent income losses associated with exiting marriage. In what follows, we interpret these stability indices as indicators of unobserved match quality, which is a core concept in the matching literature. However, we stress at the outset that this is not the only possible interpretation. For example, the stability indices may also capture monetary costs that are associated with exiting marriage, search costs that correspond to frictions on the marriage market, or costs of marriage mismatch due to incomplete information.

Formally, starting from our characterization in Proposition 1, we include a stability index

\footnotetext{
${ }^{14}$ We thank Martin Browning for pointing this out.
} 
in each restriction of individual rationality $\left(s_{m, \emptyset}^{I R}\right.$ for the male $m$ and $s_{\emptyset, w}^{I R}$ for the female $w$ ) and no blocking pair $\left(s_{m, w}^{N B P}\right.$ for the pair $\left.(m, w)\right)$. Specifically, we replace the inequalities in condition (i) by

$$
\begin{aligned}
& \left(s_{m, \emptyset}^{I R} \times y_{m, \emptyset}\right) \leq p_{m, \emptyset} q_{m, \sigma(m)}^{m}+P_{m, \emptyset} Q_{m, \sigma(m)} \text { and } \\
& \left(s_{\emptyset, w}^{I R} \times y_{\emptyset, w}\right) \leq p_{\emptyset, w} q_{\sigma(w), w}^{w}+P_{\emptyset, w} Q_{\sigma(w), w},
\end{aligned}
$$

and the inequality in condition (ii) by

$$
\left(s_{m, w}^{N B P} \times y_{m, w}\right) \leq\left(p_{m, w} q_{m, \sigma(m)}^{m}+P_{m, w}^{m} Q_{m, \sigma(m)}\right)+\left(p_{m, w} q_{\sigma(w), w}^{w}+P_{m, w}^{w} Q_{\sigma(w), w}\right),
$$

and we add the restriction $0 \leq s_{m, \emptyset}^{I R}, s_{\emptyset, w}^{I R}, s_{m, w}^{N B P} \leq 1$. Clearly, imposing $s_{m, \emptyset}^{I R}=s_{\emptyset, w}^{I R}=s_{m, w}^{N B P}=1$ obtains the original (sharp) conditions in Proposition 1. Conversely, $s_{m, \emptyset}^{I R}=s_{\emptyset, w}^{I R}=s_{m, w}^{N B P}=0$ means that income after divorce is zero, which implies that the individual rationality and no blocking pair restrictions lose any empirical bite. Generally, a lower stability index corresponds to a greater income loss associated with a particular option to exit marriage (i.e., become single or remarry). Following our above interpretation, this reveals a greater loss of unobserved match quality.

We measure the degree of stability of the data set $\mathcal{D}$ by computing

$$
\max _{s_{m, \emptyset}^{I R}, s_{\emptyset, w}^{I R}, s_{m, w}^{N B P}} \sum_{m} s_{m, \emptyset}^{I R}+\sum_{w} s_{\emptyset, w}^{I R}+\sum_{m} \sum_{w} s_{m, w}^{N B P}
$$

subject to the feasibility constraints (a) and (b) in Proposition 1 and the linear constraints (6) and (7). By solving (8), we compute a different stability index for every individual rationality constraint $\left(s_{m, \emptyset}^{I R}\right.$ and $\left.s_{\emptyset, w}^{I R}\right)$ and no blocking pair constraint $\left(s_{m, w}^{N B P}\right)$. Correspondingly, for each different exit option we can define the loss in match quality (expressed as a divorce cost) that is needed to obtain rationalizability of the observed marriage and consumption behavior. Specifically, we will calculate our match quality indicators as $\left(1-s_{m, \emptyset}^{I R}\right) \times 100$ and $\left(1-s_{\emptyset, w}^{I R}\right) \times 100$ for the individual rationality constraints (for the males $m$ and females $w$ ) and as $\left(1-s_{m, w}^{N B P}\right) \times 100$ 
for the no blocking pair constraints (for the pairs $(m, w)$ ).

Our following application will illustrate two possible uses of our stability indices and associated match quality indicators. First, for our cross-section of households, we will relate the observed heterogeneity in household characteristics to the revealed variation in unobserved match quality. This will explore which household characteristics generally correspond to more or less match quality. Next, we will use the computed values of $s_{m, \emptyset}^{I R}, s_{\emptyset, w}^{I R}$ and $s_{m, w}^{N B P}$ to rescale the original income levels $y_{m, \emptyset}, y_{\emptyset, w}$ and $y_{m, w}$, which will define an adjusted data set that is rationalizable by a stable matching. For this new data set, we will set identify household-specific sharing rules by using the linear programming method that we introduced above.

As a final remark, we note that the availability of panel data or information on actual divorces may lead to alternative interesting applications of our indices. Obviously, observed divorces would reveal more information about match quality and, therefore, the validity of our stability indices as indicators of this match quality. More ambitiously, such data would allow us to check the empirical validity of intertemporal bargaining models in which divorce costs explicitly influence the bargaining process and, ultimately, the decision to divorce. This relates to the important issues of intrahousehold commitment and renegotiation, which become crucial in dynamic analyses of household decision making. ${ }^{15}$ In the same vein, dealing with unobserved heterogeneity may be a fruitful avenue to enrich the empirical analyses that are based on our framework. ${ }^{16}$

\section{Illustrative application}

We consider a nonunitary labor supply setting in which households allocate their full income (i.e., the sum of both spouses' maximum labor income and total nonlabor income) to spouses' leisure and remaining consumption (captured by Hicksian aggregate commodities). We sub-

\footnotetext{
${ }^{15}$ Mazzocco (2007) and, more recently, Mazzocco, Ruiz and Yamaguchi (2013) and Lise and Yamada (2014) consider dynamic versions of the collective consumption model. Adams, Cherchye, De Rock and Verriest (2014) analyze such dynamic collective consumption behavior by following a revealed preference approach that is formally related to ours. Choo (2015) presents an empirical framework for dynamic marriage matching with transferable utility.

${ }^{16}$ See Blundell, Browning and Crawford (2008), Stoye and Kitamura (2013), Blundell, Kristensen and Matzkin (2014) and Hoderlein and Stoye (2014), who address similar questions in a unitary context.
} 
divide the non-leisure consumption in a private and public part. For our particular data set, private consumption is partly assignable to individual household members (i.e., we observe who consumes what for some goods) and partly nonassignable. As a first result, we obtain that our data fail the (sharp) rationalizability conditions in Proposition 1. Therefore, in a following step we compute stability indices $\left(s_{m, \emptyset}^{I R}, s_{\emptyset, w}^{I R}\right.$ and $\left.s_{m, w}^{N B P}\right)$ that allow us to construct an adjusted data set that can be rationalized. Next, we address sharing rule (set) identification by using the linear programming approach that we outlined in the previous section. Attractively, our method generates sharing rule bounds that are informatively tight. We illustrate this last feature by investigating how individuals' income shares vary with spouses' relative wages and households' full income levels.

\subsection{Data}

We apply our method to a sample of Dutch households drawn from the 2012 wave of the Dutch LISS (Longitudinal Internet Studies for the Social sciences) panel that is gathered by CentERdata. This survey, which is representative for the Dutch population, contains a rich set of economic and socio-demographic variables. ${ }^{17}$ In what follows, we first discuss our sample selection. Next, we explain how we construct individual-specific marriage markets on the basis of age.

Sample selection. The set of households used for this study was subject to the following sample selection rules. First, we only consider couples with both adults working at least 10 hours per week, and aged between 25 and 65 . We include both couples with and without children. ${ }^{18}$ Next, we excluded the self-employed to avoid issues regarding the imputation of wages and the separation of consumption from work-related expenditures. After deleting the households with important missing information (mostly, incomplete information on one of the

\footnotetext{
${ }^{17}$ Households without any Internet access are provided with a basic computer (a 'SimPC') that enables them to connect to the Internet and thereby participate in the survey. See Cherchye, De Rock and Vermeulen (2012) for a collective consumption analysis that is based on the same LISS panel (2009 wave). These authors provide more details on the characteristics of the panel and the data collection procedure.

${ }^{18}$ We implicitly assume that expenditures on children are internalized in the parents' preferences through individual or public consumption. See Bargain and Donni (2012), Cherchye, De Rock and Vermeulen (2012) and Dunbar, Lewbel and Pendakur (2013) for alternative approaches to dealing with children in collective consumption models.
} 
spouses) and some obvious outliers, we obtained a sample of 264 couples. Our following analysis also includes information on 170 male singles and 198 female singles (selected on the basis of the same sample criteria as the couples). These singles are used to construct potentially blocking pairs, which makes that we account for the possibility that a married individual may consider remarrying a single of the other gender.

Table 1 provides summary statistics for the couples in our sample. Wages are net hourly wages. Leisure is measured in hours per week. To compute leisure hours, we assume that an individual needs 8 hours per day for sleeping and personal care (i.e. leisure $=168-56$ - hours worked). Full income and (Hicksian) consumption are measured in euros per week. For completeness, Table 1 also reports on some important background information of the households under consideration.

Our data set contains assignable consumption. ${ }^{19}$ In what follows, we will treat leisure as an assignable private good. Next, the LISS data set also allows us to assign part of the remaining consumption to individual household members. ${ }^{20}$ But the main part of the observed household consumption is nonassignable. ${ }^{21}$ In our analysis, we assume that $50 \%$ of this (Hicksian aggregate) nonassignable consumption is privately consumed and $50 \%$ is publicly consumed within the household. We can motivate this choice by referring to a method proposed by Browning, Chiappori and Lewbel (2013) to compute household-specific economies of scale in a collective consumption setting. For a given household, the method computes a relative measure of scale economies as the ratio of the (sum of) the expenditures that the male and female would need as singles to buy their consumption bundles within marriage (i.e., public and private quantities evaluated at the observed market prices), divided by the actual (observed) outlay of the

\footnotetext{
${ }^{19}$ Using our notation of the previous sections, this means that part of the privately consumed quantities $q_{m, \sigma(m)}^{m}$ and $q_{\sigma(w), w}^{w}$ is effectively observed. Clearly, such information is easily included in the linear characterization in Proposition 1 through appropriately defined linear constraints, which define feasibility bounds on the variables $q_{m, \sigma(m)}^{m}$ and $q_{\sigma(w), w}^{w}$.

${ }^{20}$ The assignable good categories are food at home and outside home, tobacco, clothing, personal care products and services, medical care and health costs not covered by insurance, leisure time expenditures, (further) schooling expenditures, donations and gifts, and other personal expenditures. In our empirical analysis we treat individuals' assignable consumption as a Hicksian aggregate commodity.

${ }^{21}$ The non-assignable consumption includes mortgage, rent, utilities, transport, insurance, daycare, alimony, debt, holiday expenditures, housing expenditures, other public expenditures, and child expenditures (i.e., expenditures on assignable private goods for children). Just like for assignable consumption, our empirical exercise considers this nonassignable consumption as a Hicksian aggregate commodity.
} 
household. Clearly, more public consumption implies greater economies of scale. We compute this scale economies measure for consumption without leisure. For the above specification of private and public consumption (with $50 \%$ of the nonassignable consumption treated as public consumption), this obtains on average economies of scale of 1.372 for our sample of couples, with a standard deviation of 0.056. These figures fall in line with other estimates of scale economies that have been reported in the empirical literature on collective models (see, for example, Browning, Chiappori and Lewbel, 2013). ${ }^{22}$

Next, our method requires prices and incomes that apply to the exit options from marriage (i.e., becoming single or remarry). For our labor supply application, prices correspond to individual wages. We assume that wages outside marriage are the same as inside marriage (i.e., exiting marriage does not affect labor productivity). This may seem to be a rather strong assumption in light of the literature on marriage premiums and penalties. However, we emphasize that, in principle, the wages and incomes in the counterfactual situations of being single or with a different partner actually need not be literally observed. An alternative would be to impute these post-divorce wages and incomes, e.g. based on regressions that take account of the so-called marriage premium. ${ }^{23}$ To keep our exposition simple, we will not illustrate this more sophisticated alternative. Moreover, it can be argued that the wage rate inside marriage is probably a good benchmark when individuals compare their opportunity sets inside their current marriage and outside marriage as a single or with a different partner.

Finally, to reconstruct the potential full income in the unobserved outside options, we must define the individual nonlabor incomes after divorce. For the observed households, we use a consumption-based measure of total nonlabor income, i.e. nonlabor income equals full income minus reported consumption expenditures. Then, in our linear programming method we treat individual nonlabor incomes as unknowns (similar to the individual quantities $q_{m, \sigma(m)}^{m}, q_{m, \sigma(m)}^{w}$ and personalized prices $\left.P_{m, w}^{m}, P_{m, w}^{w}\right)$ that are subject to the restriction that they must add up

\footnotetext{
${ }^{22}$ As a robustness check, we redid all our following analyses for two alternative specifications, i.e. $25 \%$ and $75 \%$ of the nonassignable consumption treated as public consumption. Of course, these alternative choices resulted in different scale economies measures (average scale economies of, respectively, 1.186 and 1.558 for our sample of households). However, our main qualitative conclusions regarding households' sharing rules remained unaffected.

${ }^{23}$ See, for example, Korenman and Neumark (1991) for a seminal contribution.
} 


\begin{tabular}{lcccc}
\hline & Mean & St. dev. & Min. & Max. \\
\hline Male wage & 13.52 & 4.25 & 5.77 & 36.06 \\
Female wage & 11.98 & 3.31 & 1.80 & 26.96 \\
Full income & 2855.85 & 663.64 & 1256.41 & 5854.15 \\
Total private consumption & 473.72 & 156.82 & 79.04 & 1148.08 \\
Assignable male private consumption & 90.03 & 53.16 & 8.77 & 375 \\
Assignable female private consumption & 93.67 & 48.77 & 4.62 & 309.23 \\
Public consumption & 290.02 & 121.16 & 14.42 & 830.19 \\
Male leisure & 71.36 & 10.33 & 22 & 102 \\
Female leisure & 83.74 & 10.77 & 39 & 102 \\
Male age & 46.67 & 8.57 & 26 & 65 \\
Female age & 44.66 & 8.69 & 26 & 62 \\
Number of children & 1.30 & 1.1 & 0 & 4 \\
Male dummy for college degree & 0.34 & 0.47 & 0 & 1 \\
Female dummy for college degree & 0.33 & 0.47 & 0 & 1 \\
Dummy for mixed marriage & 0.14 & 0.35 & 0 & 1 \\
\hline
\end{tabular}

Table 1: Summary statistics for couples. Full income and consumption are in euros per week, wages in euros per hour and leisure in hours per week. Mixed marriage indicates a different ethnical background.

to the observed (consumption-based) total nonlabor income. Basically, given that the actual nonlabor incomes of individual males and females are unobserved, this checks whether there exists at least one feasible specification of these nonlabor incomes that rationalizes the observed behavior by a stable matching. ${ }^{24}$

Marriage market. It can hardly be assumed that all individuals in our base data set operate on the same marriage market. Most notably, there are big age differences between some males and females in our sample. To account for this, we will assume that a male (female) individual's marriage market contains all single and married women (men) who are at most 4 (9) years older and 9 (4) years younger. These bounds correspond to the 2.5th and 97.5th percentiles of

\footnotetext{
${ }^{24}$ As compared to the alternative that fixes the intrahousehold distribution of nonlabor income (e.g., $50 \%$ for each individual), this procedure to endogenously define the individual nonlabor incomes effectively gives the "benefit-of-the-doubt" to our assumption of stable matching. In that sense, we treat the (unknown) individual nonlabor incomes the same as the (unknown) individual quantities and personalized prices. However, to exclude unrealistic scenarios, we impose that individual nonlabor incomes after divorce must lie between $40 \%$ and $60 \%$ of the total nonlabor income under marriage. Next, because we define the individual nonlabor incomes endogenously, we only use the stability indices $s_{m, \emptyset}^{I R}, s_{\emptyset, w}^{I R}$ and $s_{m, w}^{N B P}$ to rescale potential (post-divorce) labor incomes (i.e., wages multiplied by total available time), and not nonlabor incomes, in our analogues of (6) and (7). This ensures that our conditions are linear in unknowns, so that we can use linear programming to compute (8). It also makes that our following concept of divorce cost is to be interpreted in terms of labor income rather than full income.
} 


\begin{tabular}{lcc}
\hline & Males & Females \\
\hline Mean & 181.79 & 173.64 \\
St. dev. & 37.10 & 40.31 \\
Minimum & 32 & 52 \\
First quartile & 173 & 149 \\
Median & 195 & 188 \\
Third quartile & 206 & 208 \\
Maximum & 216 & 215 \\
\hline
\end{tabular}

Table 2: Summary statistics on size of individual-specific marriage markets.

the age difference distribution in our sample of couples. By using this procedure, we obtain a separate (age-based) marriage market for each married individual.

Table 2 provides summary statistics on the sizes of the individual-specific marriage markets for our sample of households. On average, the marriage market for males contains 182 women (both married and single), while the average market size for women equals 174 . We also observe quite some variation across individuals. For example, the smallest and largest marriage markets for men (women) contain, respectively, 32 (52) and 216 (215) individuals.

\subsection{Rationalizability}

We begin by checking whether and to what extent the observed consumption and marriage behavior satisfies the rationalizability conditions in Proposition 1. By using the procedure outlined in Section 3, we calculate the minimal divorce costs (defined as $\left(1-s_{m, \emptyset}^{I R}\right) \times 100$, $\left(1-s_{\emptyset, w}^{I R}\right) \times 100$ and $\left.\left(1-s_{m, w}^{N B P}\right) \times 100\right)$ that we need to obtain rationalizability of our sample of couples. As indicated above, these divorce costs can be regarded as proxies for the postdivorce losses of unobserved match quality (expressed in monetary terms) that are required to represent the observed marriage allocation as stable.

Table 3 summarizes the results of this exercise. The second and third columns report on the distribution for the individual rationality constraints of males and females, respectively. The fourth and fifth columns pertain to the no blocking pair constraints. For a matched pair $(m, \sigma(m))$, the Maximum index (fourth column) refers to the highest divorce cost (or loss of match quality) necessary to neutralize all possible remarriages (i.e., the maximum of the values $\left(1-s_{m, w^{\prime}}^{N B P}\right) \times 100$ and $\left(1-s_{m^{\prime}, \sigma(m)}^{N B P}\right) \times 100$ over all $w^{\prime}$ and $\left.m^{\prime}\right)$, and the Mean index 
(fifth column) to the average divorce cost (i.e., the mean of the values $\left(1-s_{m, w^{\prime}}^{N B P}\right) \times 100$ and $\left(1-s_{m^{\prime}, \sigma(m)}^{N B P}\right) \times 100$ over all $w^{\prime}$ and $\left.m^{\prime}\right)$. Intuitively, the Maximum index is defined by the "most attractive" remarriage option (in terms of material consumption possibilities), while the Mean index pertains to the "average" remarriage option.

Table 3 shows that about 94 percent of the men and close to 100 percent of the women in our couples satisfy the sharp individual rationality constraints (without divorce costs). Moreover, it also reveals that we generally need only fairly little match quality to obtain consistency with the individual rationality constraints: on average, the associated divorce costs amount to no more than 0.21 and approximately zero percent of post-divorce full incomes for, respectively, the males and the females in our sample. These results suggest that only few individuals have an incentive to become single. Intuitively, this can be explained by the presence of public consumption in our model of stable marriage. Public consumption generates economic gains from marriage, which makes it less attractive to become single. Still, some males do require a considerable cost of divorce to meet the individual rationality requirements. For example, the maximum value in the second column of Table 3 equals 15.96 percent.

Next, we generally need higher divorce costs (i.e., greater losses of match quality) to rationalize the observed marriages in terms of the no blocking pair constraints. For example, there is no couple in our sample that satisfies the sharp constraints. However, the mean value in the fifth column (for the average remarriage option) amounts to only 0.70 percent. This suggests that the average divorce cost required to rationalize the observed marriage behavior is still fairly low. Nevertheless, the mean value in the fourth column (for the most attractive remarriage option) amounts to as much as 9.56 percent, which indicates that unobserved match quality is important to effectively neutralize all potentially blocking pairs. Just like for the individual rationality constraints, when considering the maximum values in the last line of Table 3, we learn that some couples do need a rather substantial divorce cost (or match quality loss) to rationalize their marriage behavior in terms of the no blocking pair constraints.

Table 3 shows quite some inter-household heterogeneity for the no blocking pair indices, which makes it interesting to relate this revealed variation to observable household characteristics. This can provide insight into which household types are systematically characterized 


\begin{tabular}{lcccc}
\hline & \multicolumn{2}{c}{ Individual rationality } & \multicolumn{2}{c}{ No blocking pairs } \\
& Males & Females & Maximum & Mean \\
\hline Fraction zero & 93.94 & 99.62 & 0.00 & 0.00 \\
Mean & 0.21 & 0.00 & 9.56 & 0.70 \\
St. dev. & 1.25 & 0.06 & 3.42 & 0.58 \\
Minimum & 0.00 & 0.00 & 0.00 & 0.00 \\
First quartile & 0.00 & 0.00 & 6.20 & 0.36 \\
Median & 0.00 & 0.00 & 10.30 & 0.63 \\
Third quartile & 0.00 & 0.00 & 12.57 & 0.87 \\
Maximum & 15.96 & 0.95 & 19.22 & 6.50 \\
\hline
\end{tabular}

Table 3: Cost of divorce as a fraction of post-divorce full income (in percent). Columns 2 and 3 report on the distribution of this cost for the individual rationality constraints. Columns 4 and 5 report on the household-specific no blocking pair constraints: for a matched pair, the Maximum index (Column 4) refers to the highest divorce cost, and the Mean index (Column 5) to the average divorce cost.

by more match quality than others. To this end, we conducted a regression analysis that relates our divorce cost estimates to the intrahousehold wage and age structure, the household's full income, the number of children, a dummy that captures whether the couple is a mixed marriage, and a dummy that captures whether spouses have a different education level. Because the individual-specific marriage markets vary considerably in size (see Table 2), we also condition on the sizes of the male and female marriage markets.

We carried out two OLS regressions: our first regression uses the Maximum index (summarized in the fourth column of Table 3) as dependent variable, and our second regression uses the Mean index (in the fifth column of Table 3) as dependent variable. In line with our above discussion, we interpret these indices as indicators of, respectively, the Maximum and Mean match quality (in monetary terms) that is required to rationalize the observed marriages.

The results of these exercises are reported in Table 4. We see that the size of the marriage market has a positive effect on the Maximum match quality indicator. The explanation is that greater marriage markets imply more remarriage options, which generally requires higher match quality for a marriage to be stable. It seems intuitive that this effect holds particularly true for the "most attractive" remarriage option (which defines our Maximum match quality indicator).

We also find a number of significant associations for our Mean match quality indicator. A 
negative effect applies to the household's full income. Intuitively, increasing the couple's full income implies greater consumption possibilities. In that case, it becomes more difficult to find an exit option that dominates the current marriage. Clearly, if outside options become less attractive, then we need less match quality (or divorce costs) to rationalize the observed marriage behavior. Next, the positive sign of our age variable may indicate that older couples experience higher match quality (also because of "survival" effects). See, for example, Mazzocco, Ruiz and Yamaguchi (2013) and Adams, Cherchye, De Rock and Verriest (2014) for related empirical findings.

We further observe that both the average wage and the wage difference have a positive effect on Mean match quality. The positive effect of average wage indicates that a higher potential labor income (for a given level of full income) generally requires more match quality to rationalize the observed marriage. One possible explanation is that labor income is fairly easily "portable" to other marriages and thus, if labor income constitutes a more important fraction of the household's full income, the set of attractive outside options becomes larger. Next, a larger absolute wage difference between spouses is also associated with a higher need of match quality. Again, we can give this association an intuitive interpretation. If one household member has a substantially larger wage than his/her partner, then (s)he has more attractive outside options. In turn, this can make it more difficult to rationalize the couples' marriage behavior, unless we account for a higher match quality.

Finally, children are positively associated with the Maximum and Mean match quality. Obviously, this makes intuitive sense, but we must add that the effect is far from statistically significant in our regressions. Also the remaining coefficients are insignificantly estimated, which makes it difficult to draw strong conclusions.

\subsection{Sharing rule identification}

As indicated above, by using the stability indices that underlie our results in Table 3, we can construct a new data set that is rationalizable by a stable matching. Subsequently, this allows us to set identify the decision structure underlying the observed stable marriage behavior. We do this for the sharing rule (see (4) and (5)). Because the sharing rule allocates the household's 


\begin{tabular}{lcccc}
\hline & \multicolumn{2}{c}{ Maximum match quality } & \multicolumn{2}{c}{ Mean match quality } \\
& coef. & s.e. & coef. & s.e. \\
\hline Constant & $1.969^{*}$ & 1.159 & $0.998^{* * *}$ & 0.230 \\
Average wage & -0.127 & 0.099 & $0.0128^{* * *}$ & 0.020 \\
Absolute wage difference & 0.064 & 0.045 & $0.059^{* * *}$ & 0.009 \\
Full income & -0.001 & 0.000 & $-0.001^{* * *}$ & 0.000 \\
Average age & -0.022 & 0.023 & $0.009^{*}$ & 0.005 \\
Absolute age difference & -0.089 & 0.055 & -0.010 & 0.011 \\
Children & 0.076 & 0.154 & 0.040 & 0.031 \\
Mixed marriage & -0.608 & 0.413 & 0.096 & 0.082 \\
Different education level & 0.050 & 0.291 & 0.046 & 0.058 \\
Size of male market & $0.017^{* *}$ & 0.007 & 0.001 & 0.001 \\
Size of female market & $0.048^{* * *}$ & 0.006 & -0.002 & 0.001 \\
\multicolumn{1}{c}{$\mathrm{R}^{2}$} & \multicolumn{2}{c}{0.565} & \multicolumn{2}{c}{0.398} \\
\hline
\end{tabular}

Table 4: Match quality (measured as post-divorce income loss) and household characteristics $\left(*=10\right.$ percent significance, ${ }^{* *}=5$ percent significance, ${ }^{* * *}=1$ percent significance).

full income to the individual household members by accounting for both private and public consumption (evaluated at the individuals' Lindahl prices), it is often regarded as an indicator of individual well-being. ${ }^{25}$

As a first exercise, we compare the bounds on female income shares (male shares are one minus the female shares) that are obtained by our revealed preference methodology with "naive" bounds. These naive bounds do not make use of the (theoretical) restrictions associated with a stable matching allocation, and are defined as follows: the lower bound for a female in a particular household equals the share of the value of her assignable consumption (including leisure) in this household's full income; the corresponding upper bound adds the share of nonassignable consumption in the household's full income to this lower bound. In other words, the lower (upper) bound corresponds to an extreme scenario where all the household's nonassignable consumption is allocated to the male (female).

The results are summarized in Table 5. In that table, we call the bounds that we obtain by our methodology "stable" bounds, as they correspond to a stable matching allocation on the marriage market. We compute two types of stable bounds: the first type is defined by

\footnotetext{
${ }^{25}$ We remark that some caution is in order with this interpretation. From (4) and (5), it is clear that a higher individual income share may well be due to higher Lindahl prices rather than more individual consumption and, thus, the individual needs not necessarily be better off with a higher share. See Chiappori and Meghir (2014) for further discussion and an alternative approach to conduct welfare analyses on the basis of the sharing rule.
} 
solely using the empirical implications of the individual rationality (IR) constraints, while the second type uses all (i.e., both the individual rationality and no blocking pair) constraints. Comparing the results of these two analyses provides insight into the identifying power of each category of stability restrictions. In fact, we can give our two types of stable bounds a particular interpretation in terms of two specific models of stable marriage behavior. The first type corresponds to a model with extreme search frictions, i.e. individuals do not meet other potential partners and, thus, the only exit option from marriage is to become single. By contrast, the second type of bounds corresponds to the other limiting case in which individuals have complete information on all potential new partners on their (individual-specific) marriage market.

From Table 5, we find that our stable bounds provide a substantial gain in precision compared to the naive bounds. The average difference between the upper and lower naive bounds is 21.10 percentage points, while this difference equals only 17.17 and 11.67 percentage points for our stable bounds. Further, when comparing our two types of stable bounds, we observe that both the individual rationality restrictions and no blocking pair restrictions have considerable identifying power: our stable bounds of the first type (which only use the individual rationality constraints) are much tighter than the naive bounds and, similarly, our stable bounds of the second type (which use all stability constraints) are systematically narrower than our bounds of the first type. Intuitively, this indicates that adding information on outside options (to become single or to remarry) generally enhances the precision of our identification method. Interestingly, the results also demonstrate that the stable marriage model with only the assumption of individual rationality (i.e., no information on potential new partners) can obtain informative sharing rule bounds.

Importantly, despite our minimalistic set-up, the bounds that we obtain are informatively tight. We illustrate this feature for the relation between female resource shares and, respectively, households' full incomes and intrahousehold wage ratios (i.e. female wage divided by male wage). We focus on these particular relationships because they received considerable attention in the literature on collective consumption models. It is frequently assumed in the empirical literature that bargaining power is independent of total household income; see, for 


\begin{tabular}{lccc}
\hline & Naive bounds & \multicolumn{2}{c}{ Stable bounds } \\
& & Only IR constraints & All constraints \\
\hline Mean & 21.10 & 17.17 & 11.67 \\
St. dev. & 6.90 & 6.96 & 3.93 \\
Minimum & 1.59 & 1.59 & 1.59 \\
First quartile & 16.08 & 12.44 & 9.08 \\
Median & 20.72 & 17.33 & 11.56 \\
Third quartile & 25.70 & 21.44 & 14.02 \\
Maximum & 43.67 & 43.67 & 28.97 \\
\hline
\end{tabular}

Table 5: Sharing rule identification. Percentage point differences between upper and lower bounds on female relative income shares.

instance, Lewbel and Pendakur (2008), Bargain and Donni (2012) and Dunbar, Lewbel and Pendakur (2013). These authors use this assumption to obtain point identification for resource shares. Next, the literature also provided systematic evidence that a household member's bargaining power generally increases with her/his wage; see, for example, Chiappori, Fortin and Lacroix (2002), Blundell, Chiappori, Magnac and Meghir (2007), Oreffice (2011) and Cherchye, De Rock, Lewbel and Vermeulen (2015). The underlying reasoning is that a higher wage improves the member's outside options, which in turn yields a better bargaining position within marriage.

Figure 1 presents our results for both the naive bounds and the stable bounds that use all stability constraints. Each $\bullet$ and $\boldsymbol{\Delta}$ sign in the figure represents the upper and lower bound for a given household in our sample. To help visualize the results, we included trendlines showing local sample averages of these household-specific upper and lower bounds. Firstly, it is clear from a comparison of the left panels and the right panels in the figure that the stability conditions imply a substantial increase in precision. Of course, this should not come as a surprise given that the figure is based on the same information as Table 5. Secondly, and more importantly, the figure also demonstrates that our stable bounds allow us to draw substantially stronger and more robust conclusions about the relationship between the female resource shares and the households' full incomes or intrahousehold wage ratios. The trendlines in the upper panels suggest a slightly decreasing trend, but they do not allow us to reject the hypothesis that the female's relative income share is independent of full income. The stable 
bounds make this statement stronger given the higher precision. By contrast, in the lower panels of Figure 1, we do observe a significant upward sloping pattern for the stable bounds. The pattern is considerably more pronounced for the stable bounds than for the naive bounds. It clearly indicates that a higher relative wage for the female does give her a better bargaining position and, via this channel, a larger resource share.

Summarizing, the bounds in Figure 1 show the potential of our framework to analyze the structural implications of the marriage market for household consumption patterns. It allows for an informative analysis of the intrahousehold decision process, even if we make minimal assumptions on the data at hand. Interestingly, the conclusions that we obtain regarding income and wage effects fall in line with existing results in the literature. Importantly, because of the specific set-up of our analysis, we can give these findings a structural interpretation by explaining a higher relative share in terms of better outside options on the marriage market. In our opinion, this clearly demonstrates the empirical usefulness of endogenizing the marriage matching decisions in the household consumption analysis. ${ }^{26}$

\section{Conclusion}

We have developed a novel framework to analyze the structural implications of the marriage market for household consumption behavior. It endogenizes the marriage matching decisions in the household consumption analysis by explicitly incorporating individuals' outside options. More specifically, we have defined testable revealed preference restrictions of stable marriage under the maintained assumption of Pareto efficient household consumption. Importantly, our characterization allows for intrahousehold consumption transfers but does not require individual utilities to be transferable. We have shown that this characterization provides a useful basis for identifying the intrahousehold decision structure (including the sharing rule) that underlies stable marriage behavior.

An application to Dutch household data illustrated our approach. It showed that our methodology can have substantial empirical bite in terms of providing tight sharing rule

\footnotetext{
${ }^{26}$ In this respect, see also Ackerberg and Botticini (2002), who emphasize the importance of endogenizing matching decisions in the empirical analysis of contract forms.
} 


\section{Full income}
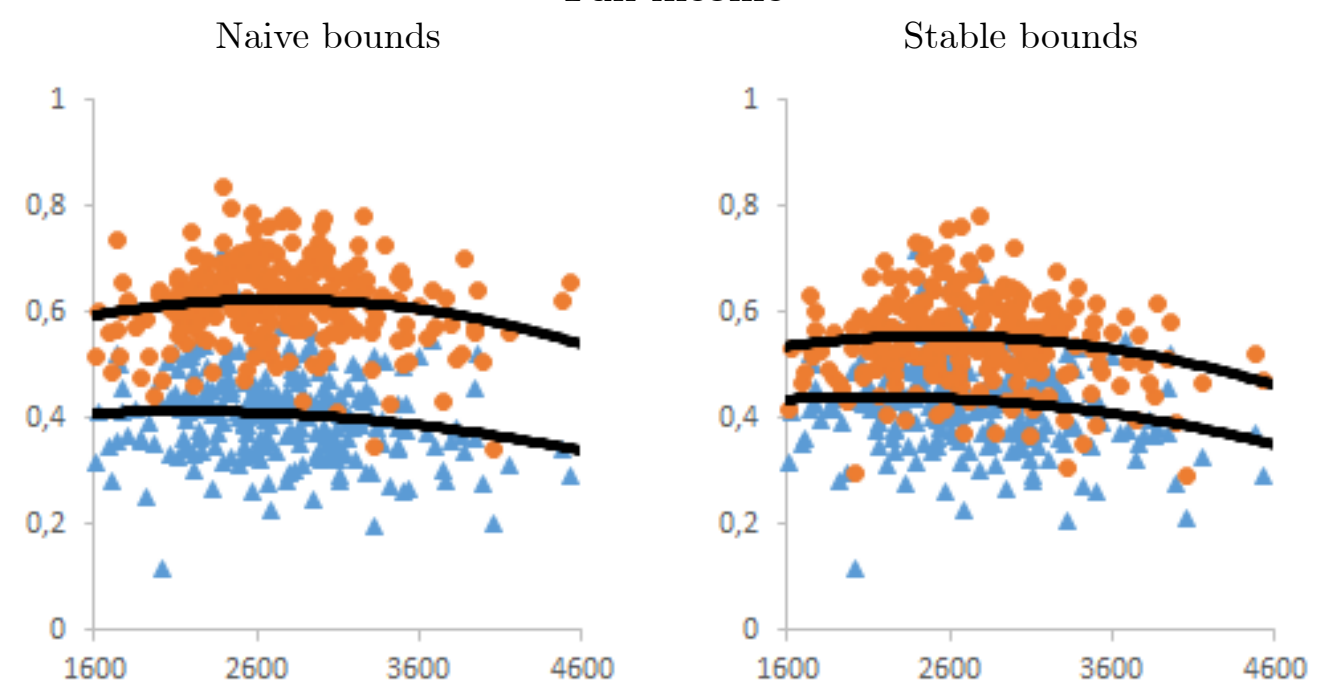

Wage ratio (female/male)

Naive bounds

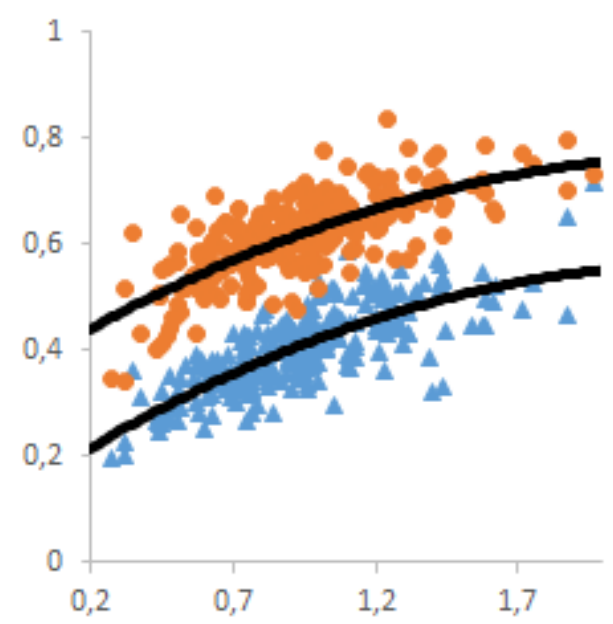

Stable bounds

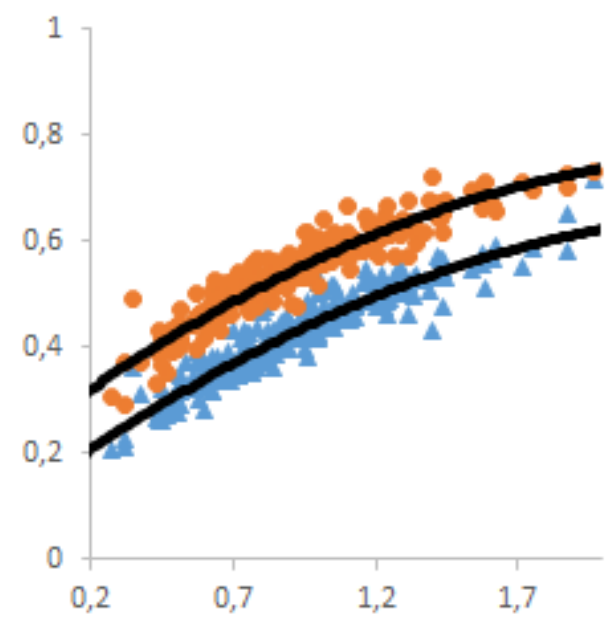

Figure 1: Sharing rule (Y-axis: female relative share), full income (X-axis in upper panels) and wage ratio (X-axis in lower panels). 
bounds. We obtained informative bounds even in the limiting case with only a single consumption observation per household and without assuming any preference homogeneity across households. It turns out that most of the identifying power comes from the no blocking pair condition for marital stability. However, also the individual rationality condition provides useful information, albeit to a lesser extent than the no blocking pair requirement.

\section{References}

[1] Ackerberg, D., and M. Botticini (2002), "Endogenous matching and the empirical determinants of contract forms", Journal of Political Economy, 110, 564-591.

[2] Adams, A., L. Cherchye, B. De Rock and E. Verriest (2014), "Consume now or later? Time inconsistency, collective choice and revealed preference", American Economic Review, 104, 4147-4183.

[3] Afriat, S. (1967), "The construction of utility functions from expenditure data", International Economic Review, 8, 67-77.

[4] Amuedo-Dorantes, C. and S. Grossbard (2007), "Cohort-level sex ratio effects on women's labor force participation", Review of Economics of the Household, 5, 249-278.

[5] Alkan, A. and D. Gale (1990), "The core of the matching game", Games and Economic Behavior, 2, 203-212.

[6] Attanasio, O. and V. Lechene (2014), "Efficient responses to targeted cash transfers", Journal of Political Economy, 122, 178-222.

[7] Bargain, O., and O. Donni (2012), "The measurement of child costs: A Rothbarth-type method consistent with scale economies and parents' bargaining", European Economic Review, 56, 792-813.

[8] Becker, G. (1973), "A theory of marriage: Part I", Journal of Political Economy, 81, $813-846$ 
[9] Blundell, R., M. Browning, L. Cherchye, I. Crawford, B. De Rock and F. Vermeulen (2015), "Sharp for SARP: nonparametric bounds on counterfactual demands", American Economic Journal: Microeconomics, 7, 43-60.

[10] Blundell, R., M. Browning, and I. Crawford (2008), "Best nonparametric bounds on demand responses", Econometrica, 76, 1227-1262.

[11] Blundell, R., P.-A. Chiappori, T. Magnac, and C. Meghir (2007), "Collective labor supply: heterogeneity and nonparticipation", Review of Economic Studies, 74, 417-445.

[12] Blundell, R., P.-A. Chiappori, and C. Meghir (2005), "Collective labor supply with children", Journal of Political Economy, 113, 1277-1306.

[13] Blundell, R., D. Kristensen, and R. Matzkin (2014), "Bounding quantile demand functions using revealed preference inequalities", Journal of Econometrics, 179, 112-127.

[14] Bourguignon, F., M. Browning, and P.-A. Chiappori (2009), "Efficient intra-household allocations and distribution factors: implications and identification", Review of Economic Studies, 76, 503-528.

[15] Browning, M, F. Bourguignon, P.-A. Chiappori, and V. Lechene (1994), "Income and outcomes: a structural model of intrahousehold allocations", Journal of Political Economy, 102, 1067-1096.

[16] Browning, M., and P.-A. Chiappori (1998), "Efficient intra-household allocations: a general characterization and empirical tests", Econometrica, 66, 1241-1278.

[17] Browning, M., P.-A. Chiappori, and V. Lechene (2010), "Distributional effects in household models: separate spheres and income pooling", Economic Journal, 120, 786-799.

[18] Browning, M., P.-A. Chiappori, and A. Lewbel (2013), "Estimating consumption economies of scale, adult equivalence scales, and household bargaining power", Review of Economic Studies 80, 1267-1303. 
[19] Browning, M., P.-A. Chiappori, and Y. Weiss (2014), Family Economics, Cambridge University Press.

[20] Cherchye, L., T. Demuynck, and B. De Rock (2011), "Revealed preference analysis of noncooperative household consumption", Economic Journal, 121, 1073-1096.

[21] Cherchye, L., T. Demuynck, and B. De Rock (2014), "Is utility transferable? A revealed preference analysis", Theoretical Economics, 10, 51-65.

[22] Cherchye, L., B. De Rock, A. Lewbel, and F. Vermeulen, F. (2015), "Sharing rule identification for general collective consumption models", Econometrica, 83, 2001-2041.

[23] Cherchye, L., B. De Rock, and F. Vermeulen (2007), "The collective model of household consumption: a nonparametric characterization", Econometrica, 75, 553-574.

[24] Cherchye, L., B. De Rock, and F. Vermeulen (2009), "Opening the black box of intrahousehold decision-making: theory and non-parametric empirical tests of general collective consumption models", Journal of Political Economy, 117, 1074-1104.

[25] Cherchye, L., B. De Rock, and F. Vermeulen (2011), "The revealed preference approach to collective consumption behavior: testing and sharing rule recovery", Review of Economic Studies, 78, 176-198.

[26] Cherchye, L., B. De Rock and F. Vermeulen (2012), "Married with children: a collective labor supply model with detailed time use and intrahousehold expenditure information", American Economic Review, 102, 3377-3405.

[27] Cherchye, L., and F. Vermeulen (2008), "Nonparametric analysis of household labor supply: goodness-of-fit and power of the unitary and the collective model", Review of Economics and Statistics, 90, 267-274.

[28] Chiappori, P.A. (1988), "Rational household labor supply", Econometrica, 56, 63-89.

[29] Chiappori, P.A. (1992), "Collective labor supply and welfare", Journal of Political Economy, 100, 437-467. 
[30] Chiappori, P.A. (2010), "Testable implications of transferable utility", Journal of Economic Theory, 145, 1302-1317.

[31] Chiappori, P.A., and I. Ekeland (2006), "The micro economics of group behavior: general characterization", Journal of Economic Theory, 130, 1-26.

[32] Chiappori, P.A., and I. Ekeland (2009), "The micro economics of efficient group behavior: identification", Econometrica, 77, 763-799.

[33] Chiappori, P.-A., B. Fortin, and G. Lacroix (2002), "Marriage market, divorce legislation and household labor supply", Journal of Political Economy, 110, 37-72.

[34] Chiappori, P.-A. and E. Gugl (2015), "Transferable utility and demand functions: a complete characterization", working paper, Columbia University.

[35] Chiappori, P.-A., M. Iyigun, J. Lafortune, and Y. Weiss (2015), "Changing the rules midway: the impact of granting alimony rights on existing and newly-formed partnerships", Economic Journal, forthcoming.

[36] Chiappori, P.-A. and C. Meghir (2014), "Intra-household welfare", Cowles Foundation working paper no. 1949, Yale University.

[37] Chiappori, P.-A., S. Oreffice, and C. Quintana-Domeque (2012), "Fatter attraction: Anthropometric and socioeconomic matching on the marriage market", Journal of Political Economy, 120, 659-695.

[38] Chiappori, P.-A., and P. Reny (2016), "Matching to share risk", Theoretical Economics, $11,227-251$.

[39] Chiappori, P.-A. and B. Salanié (2015), "The econometrics of matching models", Journal of Economic Literature, forthcoming.

[40] Choo, E. (2015), "Dynamic marriage matching: and empirical framework", Econometrica, $83,1373-1423$. 
[41] Choo, E. and S. Seitz (2013), "The Collective Matching Model: Identification, Estimation and Testing", in Advances in Econometrics, Volume 32: Structural Econometric Models, ed. E. Choo and M. Shum, Emerald Publishing Group, forthcoming.

[42] Choo, E., and A. Siow (2006), "Who marries whom and why", Journal of Political Economy, 114, 175-201.

[43] Clark, S. (2006), "Uniqueness of stable matchings", Contributions to Theoretical Economics, 6, Article 8, Berkeley Electronic Press.

[44] Couprie, H., E. Peluso, and A. Trannoy (2010), "Is power more evenly balanced in poor households?", Journal of Public Economics, 94, 493-507.

[45] Del Boca, D., and C. Flinn (2014), "Household behavior and the marriage market", Journal of Economic Theory, 150, 515-550.

[46] Diewert, E. (1973), "Afriat and revealed preference theory", Review of Economic Studies, 40, 419-426.

[47] Dunbar, G., A. Lewbel, and K. Pendakur (2013), "Children's resources in collective households: identification, estimation and an application to child poverty in Malawi", American Economic Review, 103, 438-471.

[48] Dupuy, A., and A. Galichon (2014), "Personality traits and the marriage market", Journal of Political Economy, 122, 1271-1319.

[49] Echenique, F., S. Lee, M. Shum, M., and B. Yenmez (2013), "The revealed preference theory of stable and extremal stable matchings", Econometrica, 81, 153-172.

[50] Eeckhout, J. (2000), "On the uniquess of stable marriage matchings", Economics Letters, $69,1-8$.

[51] Gale, L.S., and D. Shapley (1962), "College admissions and the stability of marriage", American Mathematical Monthly, 69, 9-15. 
[52] Galichon, A., and B. Salanié (2014), "Cupid's invisible hand: social surplus and identification in matching models", Working Paper, Columbia University.

[53] Galichon, A., S.D. Kominers and S. Weber (2015), "An empirical framework for matching with imperfectly transferable utility", Working Paper, Sciences Po.

[54] Hoderlein, S., and J. Stoye (2014), "Revealed preferences in a heterogeneous population", Review of Economics and Statistics, 96, 197-213.

[55] Houthakker, H. (1950), "Revealed preference and the utility function", Economica, 17, $159-174$.

[56] Jacquemet, N., and J.-M. Robin (2013), "Assortative matching and search with labor supply and home production", CeMMAP working paper CWP07/13.

[57] Korenman, S. and D. Neumark (1991), "Does marriage really make men more productive?", Journal of Human Resources, 26, 282-307.

[58] Lechene, V., and I. Preston (2011), "Noncooperative household demand", Journal of Economic Theory, 146, 504-527.

[59] Legros, P, and A.F. Newman (2007), "Beauty is a beast, frog is a prince: assortative matching with nontransferabilities", Econometrica 75 1073-1102.

[60] Legros, P., and A.F. Newman (2010), "Co-ranking mates: assortative matching in marriage markets", Economics Letters, 106, 177-179.

[61] Lewbel, A., and K. Pendakur (2008), "Estimation of collective household models with Engel curves", Journal of Econometrics, 147, 350-358.

[62] Lise, J., and S. Seitz (2011), "Consumption inequality and intra-household allocations", Review of Economic Studies, 78, 328-355.

[63] Lise, J., and K. Yamada (2014), "Household sharing and commitment: evidence from panel data on individual expenditures and time use", Working paper, University College London. 
[64] Liu, Q., G.J. Mailath, A. Postlewaite and L. Samuelson (2014), "Stable matching with incomplete information", Econometrica 82, 541-587.

[65] Lundberg, S., and R. Pollak (2003), "Efficiency in marriage", Review of Economics of the Household, 1, 153-167.

[66] Mazzocco, M. (2007), "Household intertemporal behaviour: a collective characterization and a test of commitment", Review of Economic Studies 74, 857-895.

[67] Mazzocco, M., C. Ruiz, and S. Yamaguchi (2013), "Labor supply, wealth dynamics and marriage decisions", Working Paper, University of California at Los Angeles.

[68] Oreffice, S. (2011), "Sexual orientation and household decision making. Same-sex couples balance of power and labor supply choices", Labour Economics, 18, 145-158.

[69] Samuelson, P. (1938), "A note on the pure theory of consumers behaviour", Economica, $5,61-71$.

[70] Samuelson, P. (1948), "Consumption theory in terms of revealed preference", Economica, $15,243-253$

[71] Shapley, L. S., and M. Shubik, (1972), "The assignment game I: the core", International Journal of Game Theory, 1, 111-130.

[72] Stoye, J., and Y. Kitamura (2013), "Nonparametric analysis of random utility models: testing", CeMMAP Working Papers CWP36/13.

[73] Varian, H. (1982), "The nonparametric approach to demand analysis", Econometrica, 50, 945-972.

\section{Appendix A: A necessary and sufficient condition for rational- izability by a stable matching (for online publication)}

Proposition 2 presents revealed preference conditions for a data set $\mathcal{D}$ to be rationalizable in the sense of Definition 5. These conditions are necessary and sufficient for rationalizability, and 
provide the basis for the necessary conditions in Proposition 1 in the main text. Importantly, as also discussed in Section 3 of the main text, the following necessary and sufficient conditions are nonlinear in nature, which makes them substantially more difficult to operationalize than the necessary conditions in Proposition 1.

Proposition 2 The data set $\mathcal{D}$ is rationalizable by a stable matching if and only if there exist

a. for each matched pair $m \in M$ and $\sigma(m) \in W$, individual quantities $q_{m, \sigma(m)}^{m}, q_{m, \sigma(m)}^{\sigma(m)} \in \mathbb{R}_{+}^{n}$ that satisfy

$$
q_{m, \sigma(m)}^{m}+q_{m, \sigma(m)}^{\sigma(m)}=q_{m, \sigma(m)}
$$

which define a matching allocation $\left\{q_{m, \sigma(m)}^{m}, q_{m, \sigma(m)}^{\sigma(m)}, Q_{m, \sigma(m)}\right\}_{m \in M}$,

b. for each unmatched pair $m \in M$ and $w \in W$ (with $\sigma(m) \neq w$ ), individual quantities $q_{m, w}^{m}, q_{m, w}^{w} \in \mathbb{R}_{+}^{n}$ and public quantities $Q_{m, w} \in \mathbb{R}_{+}^{k}$ that satisfy

$$
p_{m, w}\left(q_{m, w}^{m}+q_{m, w}^{w}\right)+P_{m, w} Q_{m, w}=y_{m, w}
$$

c. for each male $m \in M$, private quantities $q_{m, \emptyset}^{m} \in \mathbb{R}_{+}^{n}$, and public quantities $Q_{m, \emptyset} \in \mathbb{R}_{+}^{k}$, that satisfy

$$
p_{m, \emptyset} q_{m, \emptyset}^{m}+P_{m, \emptyset} Q_{m, \emptyset}=y_{m, \emptyset},
$$

d. for each female $w \in W$, private quantities $q_{\emptyset, w}^{w} \in \mathbb{R}_{+}^{n}$ and public quantities $Q_{\emptyset, w} \in \mathbb{R}_{+}^{k}$ that satisfy

$$
p_{\emptyset, w} q_{\emptyset, w}^{w}+P_{\emptyset, w} Q_{\emptyset, w}=y_{\emptyset, w}
$$

e. for each pair $(m, w)(m \in M, w \in W)$, personalized prices $P_{m, w}^{m}, P_{m, w}^{w} \in \mathbb{R}_{++}^{k}$ that satisfy

$$
P_{m, w}^{m}+P_{m, w}^{w}=P_{m, w}
$$

as well as strictly positive Afriat numbers $U_{m, w}^{m}, U_{m, \emptyset}^{m}, U_{m, w}^{w}, U_{\emptyset, w}^{w}$ and $\delta_{m, w}, \delta_{m, \emptyset}, \lambda_{m, w}, \lambda_{\emptyset, w}$ (for any $m \in M$ and $w \in W$ ) that simultaneously meet the following constraints: 
i. Afriat inequalities for all males $m \in M$, i.e. (for any $w, w^{\prime} \in W$ )

$$
\begin{aligned}
& U_{m, w}^{m}-U_{m, w^{\prime}}^{m} \leq \delta_{m, w^{\prime}}\left(p_{m, w^{\prime}}\left(q_{m, w}^{m}-q_{m, w^{\prime}}^{m}\right)+P_{m, w^{\prime}}^{m}\left(Q_{m, w}-Q_{m, w^{\prime}}\right)\right), \\
& U_{m, w}^{m}-U_{m, \emptyset}^{m} \leq \delta_{m, \emptyset}\left(p_{m, \emptyset}\left(q_{m, w}^{m}-q_{m, \emptyset}^{m}\right)+P_{m, \emptyset}\left(Q_{m, w}-Q_{m, \emptyset}\right)\right), \\
& U_{m, \emptyset}^{m}-U_{m, w^{\prime}}^{m} \leq \delta_{m, w^{\prime}}\left(p_{m, w^{\prime}}\left(q_{m, \emptyset}^{m}-q_{m, w^{\prime}}^{m}\right)+P_{m, w^{\prime}}^{m}\left(Q_{m, \emptyset}-Q_{m, w^{\prime}}\right)\right),
\end{aligned}
$$

ii. Afriat inequalities for all females $w \in W$, i.e. (for any $\left.m, m^{\prime} \in M\right)$

$$
\begin{aligned}
& U_{m, w}^{w}-U_{m^{\prime}, w}^{w} \leq \lambda_{m^{\prime}, w}\left(p_{m^{\prime}, w}\left(q_{m, w}^{w}-q_{m^{\prime}, w}^{w}\right)+P_{m^{\prime}, w}^{w}\left(Q_{m, w}-Q_{m^{\prime}, w}\right)\right), \\
& U_{m, w}^{w}-U_{\emptyset, w}^{w} \leq \lambda_{\emptyset, w}\left(p_{\emptyset, w}\left(q_{m, w}^{w}-q_{\emptyset, w}^{w}\right)+P_{\emptyset, w}\left(Q_{m, w}-Q_{\emptyset, w}\right)\right) \\
& U_{\emptyset, w}^{w}-U_{m, w}^{w} \leq \lambda_{m, w}\left(p_{m, w}\left(q_{\emptyset, w}^{w}-q_{m, w}^{w}\right)+P_{m, w}^{w}\left(Q_{\emptyset, w}-Q_{m, w}\right)\right)
\end{aligned}
$$

iii. individual rationality restrictions for all males $m \in M$ and females $w \in W$, i.e.

$$
\begin{gathered}
U_{m, \sigma(m)}^{m} \geq U_{m, \emptyset}^{m}, \\
U_{\sigma(w), w}^{w} \geq U_{\emptyset, w}^{w},
\end{gathered}
$$

iv. no blocking pair restrictions for all males $m \in M$ and females $w \in W$, i.e.

$$
\begin{aligned}
U_{m, \sigma(m)}^{m} & \geq U_{m, w}^{m}, \\
U_{\sigma(w), w}^{w} & \geq U_{m, w}^{w} .
\end{aligned}
$$

Thus, a necessary and sufficient condition for a data set $\mathcal{D}$ to be rationalizable by a stable matching is that it simultaneously satisfies the conditions (a)-(e) and (i)-(iv). Interestingly, the different conditions can be given a specific interpretation. First, the adding up constraints in (a)-(d) specify feasibility restrictions on the unknown quantities. In particular, condition (a) pertains to individual quantities for matched pairs $(m, \sigma(m))$, condition (b) to individual quantities and public quantities for unmatched pairs $(m, w)$, condition (c) to private and public quantities of males $m$ when single and, finally, condition (d) to private and public quantities 
of females $w$ when single.

Next, condition (e) defines a formally similar feasibility constraint on the personalized prices $P_{m, w}^{m}$ and $P_{m, w}^{w}$ (for any matched or unmatched pair). Intuitively, these personalized prices represent the willingness-to-pay of individual members for the public consumption. Because they must add up to the actual prices $P_{m, w}$, they can actually be interpreted as Lindahl prices that correspond to a Pareto optimal provision of public goods.

Proposition 2 requires the existence of feasible quantities and prices that simultaneously meet the rationalizability conditions (i)-(iv). These rationalizability conditions are defined in terms of so-called Afriat numbers (after Afriat, 1967). First, the Afriat numbers $U_{m, w}^{m}, U_{m, \emptyset}^{m}$ represent male $m$ 's utilities in alternative decision situations (respectively, in the pair $(m, w)$ and as a single). A directly similar interpretation applies to the Afriat numbers $U_{m, w}^{w}$ and $U_{\emptyset, w}^{w}$, which represent female $w$ 's utilities. Next, the Afriat numbers $\delta_{m, w}, \delta_{m, \emptyset}$ (for male $m$ ) and $\lambda_{m, w}, \lambda_{\emptyset, w}$ (for female $w$ ) can be interpreted as marginal utilities of individual expenditures (or Lagrange multipliers) in the respective decision scenarios (using, for a given pair $(m, w)$, the personalized prices $P_{m, w}^{m}$ and $P_{m, w}^{w}$ to allocate public good expenditures to the individuals $m$ and $w)$.

Then, the inequalities in conditions (i) and (ii) make sure that there exist (non-negative, continuous, strictly increasing and concave) utility functions $u^{m}$ and $u^{w}$ that explain the data. First, the inequalities ensure that, for all matched couples, these functions satisfy the Pareto efficiency criterion in Definition $1 .{ }^{27}$ Next, they also guarantee that the Afriat numbers $U_{m, \emptyset}^{m}$, $U_{\emptyset, w}^{w}$ solve the individual maximization problems (1) and (2), and that the numbers $U_{m, w}^{m}$ and $U_{m, w}^{w}$ solve the maximization problem (3) (so that $U_{m, w}^{m}=\psi_{m, w}\left(U_{m, w}^{w}\right)$ ), i.e. $U_{m, w}^{m}$ and $U_{m, w}^{w}$ represent utilities that are situated on the Pareto frontier of the couple $(m, w)$. Given this, the conditions (iii) and (iv) impose consistency with the individual rationality criterion in Definition 2 and the no blocking pairs criterion in Definition 3. Note that the latter criterion is expressed in an alternative form. More specifically, given that the function $\psi_{m, w}\left(\bar{u}^{w}\right)$ is continuous and strictly decreasing (by Lemma 1), it is easy to see that the no blocking pair

\footnotetext{
${ }^{27}$ See in particular Cherchye, De Rock and Vermeulen (2011), who present a revealed preference characterization of Pareto efficient (or collectively rational) household consumption in a setting that is formally similar to ours. The Afriat inequalities in their Proposition 1 are contained in the constraints (i) and (ii) of Proposition 2.
} 
condition in Definition 3 is equivalent to the requirement that, for any man $m$ and woman $w$, there must exist at least one combination of $U_{m, w}^{m}$ and $U_{m, w}^{w}$ such that

$$
\begin{gathered}
U_{m, w}^{m}=\psi_{m, w}\left(U_{m, w}^{w}\right) \\
U_{m, w}^{m} \leq u^{m}\left(q_{m, \sigma(m)}^{m}, Q_{m, \sigma(m)}\right) \text { and } U_{m, w}^{w} \leq u^{w}\left(q_{\sigma(w), w}^{w}, Q_{\sigma(w), w}\right) .
\end{gathered}
$$

\section{Appendix B: Proofs (for online publication)}

\section{Preliminaries}

We begin by proving the following lemma. ${ }^{28}$

Lemma 1 The function $\psi_{m, w}\left(\bar{u}^{w}\right)$ is strictly decreasing and continuous over the interval $\left[0, \bar{U}_{m, w}^{w}\right]$.

Proof. Consider two utility levels $\bar{u}^{w}, \bar{u}^{w \prime}$ with $\bar{U}_{m, w}^{w} \geq \bar{u}^{w}>\bar{u}^{w \prime} \geq 0$. Given that every solution to (3) with utility level $\bar{u}^{w}$ is also feasible with the utility level $\bar{u}^{w \prime}$ (by strict monotonicity of the utility functions), we have that $\psi_{m, w}\left(\bar{u}^{w \prime}\right) \geq \psi_{m, w}\left(\bar{u}^{w}\right)$.

Let $q_{m, w}^{w}$ be part of the optimal solution for utility level $\bar{u}^{w}$, then $q_{m, w}^{w}$ is strictly positive for at least one good. Indeed, otherwise we have $u^{w}\left(0, Q_{m, w}\right)=0$ by assumption, which contradicts the inequality $u^{w}\left(0, Q_{m, w}\right) \geq \bar{u}^{w}>\bar{u}^{w \prime} \geq 0$. Given the continuity and strict monotonicity of the utility function $u^{w}$, we can take a tiny bit of these private goods from $w$ and give them to $m$ in such a way that $w$ still receives utility level $\bar{u}^{w \prime}$ and the budget constraint is still satisfied. From this redistribution, we see that the utility level of $m$ strictly increases, which means that the optimal solution must also strictly increase. This shows that $\psi_{m, w}\left(\bar{u}^{w \prime}\right)>\psi_{m, w}\left(\bar{u}^{w}\right)$.

To show continuity, we consider

$$
\begin{gathered}
\xi_{m, w}\left(\bar{u}^{m}\right)=\max _{q_{m, w}^{m}, q_{m, w}^{w}, Q_{m, w}} u^{w}\left(q_{m, w}^{w}, Q_{m, w}\right) \\
\text { s.t. } p_{m, w}\left(q_{m, w}^{m}+q_{m, w}^{w}\right)+P_{m, w} Q_{m, w} \leq y_{m, w}, \\
u^{m}\left(q_{m, w}^{m}, Q_{m, w}\right) \geq \bar{u}^{m} .
\end{gathered}
$$

\footnotetext{
${ }^{28}$ The proofs of our main results are given in Appendix B.
} 
The functions $\xi_{m, w}$ and $\psi_{m, w}$ are each other's inverse. To see this, assume that $\bar{u}^{w}=\xi_{m, w}\left(\bar{u}^{m}\right)$ and let $\left(q_{m, w}^{m}, q_{m, w}^{w}, Q_{m, w}\right)$ be the solution to the woman's optimization problem given $\bar{u}^{m}$. Clearly, this bundle satisfies all restrictions for the man's optimization problem, so $\psi_{m, w}\left(\bar{u}^{w}\right) \geq$ $\bar{u}^{m}$.

We can prove $\psi_{m, w}\left(\bar{u}^{w}\right)=\bar{u}^{m}$ by contradiction. Assume that $\psi_{m, w}\left(\bar{u}^{w}\right)>\bar{u}^{m}$ and let $\left(q_{m, w}^{m}, q_{m, w}^{w}, Q_{m, w}\right)$ be the optimal solution to the man's optimization problem for $\bar{u}^{w}$. This allocation is also feasible for the woman's optimization problem given $\bar{u}^{m}$. Moreover, $q_{m, w}^{m}$ is strictly positive for at least one good. Then, consider reallocating a tiny bit of these private goods from $m$ and give them to $w$ in such a way that $m$ still receives utility level $\bar{u}^{m}$ and the budget constraint is still satisfied. This allows the woman to reach a utility level strictly above $\bar{u}^{w}$. Thus, we obtain that $\xi_{m, w}\left(\bar{u}^{m}\right)>\bar{u}^{w}$, which gives the wanted contradiction.

We conclude that the function $\xi_{m, w}$ is a strictly monotone (invertible) function from an interval to an interval. As such, it must be continuous.

Given this lemma, we can apply a general result of Alkan and Gale (1990) to show existence of a stable matching allocation. ${ }^{29}$

Proposition 3 For any set of men $M$ and women $W$ with, for all $m \in M$ and $w \in W$, utility functions $u^{m}$ and $u^{w}$, and given the incomes $y_{m, w}, y_{m, \emptyset}, y_{\emptyset, w}$ and prices $p_{m, w}, p_{m, \emptyset}, p_{\emptyset, w}, P_{m, w}$, $P_{m, \emptyset}, P_{\emptyset, w}$, there exists at least one matching $\sigma$ that defines a stable matching allocation.

\section{Proof of Proposition 1}

This result defines necessary conditions for rationalizability that are based on the necessary and sufficient conditions in Proposition 2, which is presented in Appendix A. First, conditions (a) and (e) in Proposition 2 define the constraints

$$
q_{m, \sigma(m)}^{m}+q_{m, \sigma(m)}^{w}=q_{m, \sigma(m)} \text { and } P_{m, w}^{m}+P_{m, w}^{w}=P_{m, w}
$$

Next, the individual rationality constraints (iii) together with the Afriat inequalities (i)

\footnotetext{
${ }^{29}$ Because the result follows directly from Theorem 1 of Alkan and Gale (1990), we need not include a formal proof.
} 
(for male $m$ ) and (ii) (for female $w$ ) in Proposition 2 give

$$
\begin{aligned}
0 & \leq\left[p_{m, \emptyset}\left(q_{m, \sigma(m)}^{m}-q_{m, \emptyset}^{m}\right)+P_{m, \emptyset}\left(Q_{m, \sigma(m)}-Q_{m, \emptyset}\right)\right] \\
0 & \leq\left[p_{\emptyset, w}\left(q_{\sigma(w), w}^{w}-q_{\emptyset, w}^{w}\right)+P_{\emptyset, w}\left(Q_{\sigma(w), w}-Q_{\emptyset, w}\right)\right] .
\end{aligned}
$$

In turn, this obtains

$$
\begin{aligned}
& y_{m, \emptyset} \leq p_{m, \emptyset} q_{m, \sigma(m)}^{m}+P_{m, \emptyset} Q_{m, \sigma(m)}, \\
& y_{\emptyset, w} \leq p_{\emptyset, w} q_{\sigma(w), w}^{w}+P_{\emptyset, w} Q_{\sigma(w), w} .
\end{aligned}
$$

Similarly, the no blocking pairs condition (iv) together with the Afriat inequalities (i) and (ii) give that, for all $m, w$ such that $\sigma(m) \neq w$,

$$
\begin{aligned}
0 & \leq\left[p_{m, w}\left(q_{m, \sigma(m)}^{m}-q_{m, w}^{m}\right)+P_{m, w}^{m}\left(Q_{m, \sigma(m)}-Q_{m, w}\right)\right] \\
0 & \leq\left[p_{m, w}\left(q_{\sigma(m), w}^{w}-q_{m, w}^{w}\right)+P_{m, w}^{w}\left(Q_{\sigma(w), w}-Q_{m, w}\right)\right] .
\end{aligned}
$$

The first inequality states that the man $m$ should not prefer his allocation in $(m, w)$ over his matching allocation (in revealed preference terms). The second condition does the same for woman $w$. Now, adding these two equations together yields

$$
y_{m, w} \leq p_{m, w} q_{m, \sigma(m)}^{m}+p_{m, w} q_{\sigma(w), w}^{w}+P_{m, w}^{m} Q_{m, \sigma(m)}+P_{m, w}^{w} Q_{\sigma(w), w}
$$

\section{Proof of Proposition 2}

Necessity. As a first step to deriving our revealed preference characterization, we define the first order conditions that are used to formulate this characterization. In particular, we consider these conditions for the optimization models that underlie our criteria of individual rationality and no blocking pairs: $:^{30}$

\footnotetext{
${ }^{30}$ We remark the formal similarity between the Pareto efficiency criterion in Definition 1 and the no blocking pair condition in Definition 3. Essentially, the condition in Definition 3 reduces to the one in Definition 1 for $(m, w)$ with $w=\sigma(m)$. Therefore, we can follow a directly analogous reasoning as under item 2 . below to obtain the rationalizability conditions in Proposition 2 that pertain to our Pareto efficiency requirement (compare with
} 
1. We begin with the two optimization problems for individual rationality. First, we consider the problem

$$
\begin{aligned}
\left(q_{m, \emptyset}^{m}, Q_{m, \emptyset}\right)= & \arg \max _{q^{m}, Q} u^{m}\left(q^{m}, Q\right) \\
& \text { s.t. } p_{m, \emptyset} q^{m}+P_{m, \emptyset} Q \leq y_{m, \emptyset},
\end{aligned}
$$

i.e. $\left(q_{m, \emptyset}^{m}, Q_{m, \emptyset}\right)$ represents the optimal allocation for $m$ if he spends the income $y_{m, \emptyset}$. The first order conditions yield

$$
\begin{aligned}
& \frac{\partial u^{m}\left(q_{m, \emptyset}^{m}, Q_{m, \emptyset}\right)}{\partial q^{m}} \leq \delta_{m, \emptyset} p_{m, \emptyset} \\
& \frac{\partial u^{m}\left(q_{m, \emptyset}^{m}, Q_{m, \emptyset}\right)}{\partial Q} \leq \delta_{m, \emptyset} P_{m, \emptyset}
\end{aligned}
$$

where $\delta_{m, \emptyset}$ is the Lagrange multiplier associated with the budget constraint and the expressions on the left hand side of the inequalities represent subdifferentials of the utility function $u^{m}$.

Similarly, for the problem

$$
\begin{array}{r}
\left(q_{\emptyset, w}^{w}, Q_{\emptyset, w}\right)= \\
\arg \max _{q^{w}, Q} u^{w}\left(q^{w}, Q\right) \\
\text { s.t. } p_{\emptyset, w} q^{w}+P_{\emptyset, w} Q \leq y_{\emptyset, w},
\end{array}
$$

we get the conditions

$$
\begin{aligned}
& \frac{\partial u^{w}\left(q_{\emptyset, w}^{w}, Q_{\emptyset, w}\right)}{\partial q^{w}} \leq \lambda_{\emptyset, w} p_{\emptyset, w}, \\
& \frac{\partial u^{w}\left(q_{\emptyset, w}^{w}, Q_{\emptyset, w}\right)}{\partial Q} \leq \lambda_{\emptyset, w} P_{\emptyset, w},
\end{aligned}
$$

where $\lambda_{\emptyset, w}$ is the Lagrange multiplier associated with the budget constraint.

2. Let us then turn to the optimization problems for no blocking pairs. Here, the optimizaCherchye, De Rock and Vermeulen, 2011). For compactness, we do not include this reasoning here. 
tion problem is defined as

$$
\begin{aligned}
& \left(q_{m, w}^{m}, q_{m, w}^{w}, Q_{m, w}\right)=\underset{q^{m}, Q}{\arg \max _{1}} u^{m}\left(q^{m}, Q\right) \\
& \text { s.t. } p_{m, w} q^{m}+P_{m, w} Q \leq y_{m, w}, \\
& \qquad u^{w}\left(q^{w}, Q\right) \geq U_{m, w}^{w} .
\end{aligned}
$$

i.e. $\left(q_{m, w}^{m}, q_{m, w}^{w}, Q_{m, w}\right)$ represents the allocation chosen by $m$ if he could freely spend the entire income $y_{m, w}$ given that $w$ should receive utility level $U_{m, w}^{w}$. The corresponding first order conditions give

$$
\begin{aligned}
\frac{\partial u^{m}\left(q_{m, w}^{m}, Q_{m, w}\right)}{\partial q^{m}} & \leq \delta_{m, w} p_{m, w}, \\
\mu_{m, w} \frac{\partial u^{w}\left(q_{m, w}^{w}, Q_{m, w}\right)}{\partial q^{w}} & \leq \delta_{m, w} p_{m, w}, \\
\frac{\partial u^{m}\left(q_{m, w}^{m}, Q_{m, w}\right)}{\partial Q}+\mu_{m, w} \frac{\partial u^{w}\left(q_{m, w}^{m}, Q_{m, w}\right)}{\partial Q} & \leq \delta_{m, w} P_{m, w},
\end{aligned}
$$

where $\delta_{m, w}$ is the Lagrange multiplier associated with the budget constraint and $\mu_{m, w}$ is the Lagrange multiplier associated with the utility constraint.

In what follows, we use $\lambda_{m, w}=\delta_{m, w} / \mu_{m, w}, \frac{\partial u^{w}\left(q_{m, w}^{w}, Q_{m, w}\right)}{\partial Q}=\lambda_{m, w} P_{m, w}^{w}$ and $P_{m, w}^{m}=$ $P_{m, w}-P_{m, w}^{w}\left(\right.$ which implies $\left.\frac{\partial u^{m}\left(q_{m, w}^{m}, Q_{m, w}\right)}{\partial Q} \leq \delta_{m, w} P_{m, w}^{m}\right)$.

In a final step, we can define the characterization in Proposition 2 by combining the above first order conditions with the postulated concavity property of the utility functions $u^{m}$ and $u^{w}$. In particular, concavity implies (for any $q^{m \prime}, q^{w \prime}, q^{m \prime \prime}, q^{w \prime \prime} \in \mathbb{R}_{+}^{n}$ and $Q^{\prime}, Q^{\prime \prime} \in \mathbb{R}_{+}^{k}$ )

$$
\begin{aligned}
u^{m}\left(q^{m \prime}, Q^{\prime}\right)-u^{m}\left(q^{m \prime \prime}, Q^{\prime \prime}\right) & \leq \frac{\partial u^{m}\left(q^{m \prime \prime}, Q^{\prime \prime}\right)}{\partial q^{m}}\left(q^{m \prime}-q^{m \prime \prime}\right)+\frac{\partial u^{m}\left(q^{m \prime \prime}, Q^{m \prime \prime}\right)}{\partial Q}\left(Q^{\prime}-Q^{\prime \prime}\right) \\
u^{w}\left(q^{w \prime}, Q^{\prime}\right)-u^{w}\left(q^{w \prime \prime}, Q^{\prime \prime}\right) & \leq \frac{\partial u^{w}\left(q^{w \prime \prime}, Q^{\prime \prime}\right)}{\partial q^{w}}\left(q^{w \prime}-q^{w \prime \prime}\right)+\frac{\partial u^{w}\left(q^{w \prime \prime}, Q^{w \prime \prime}\right)}{\partial Q}\left(Q^{\prime}-Q^{\prime \prime}\right)
\end{aligned}
$$

Then, we obtain the rationalizability conditions in Proposition 2 by using $u^{m}\left(q_{m, w}^{m}, Q_{m, w}\right)=$ $U_{m, w}^{m}$, and $u^{w}\left(q_{m, w}^{w}, Q_{m, w}\right)=U_{m, w}^{w}(m \in M \cup\{\varnothing\}$ and $w \in W \cup\{\varnothing\})$. 
Sufficiency. To obtain the sufficiency result, we consider

$$
\begin{aligned}
u^{m}\left(q^{m}, Q\right) & =\min _{w \in W \cup\{\varnothing\}}\left[U_{m, w}^{m}+\delta_{m, w}\left(p_{m, w}\left(q^{m}-q_{m, w}^{m}\right)+P_{m, w}^{m}\left(Q-Q_{m, w}\right)\right)\right], \\
u^{w}\left(q^{w}, Q\right) & =\min _{m \in M \cup\{\varnothing\}}\left[U_{m, w}^{w}+\lambda_{m, w}\left(p_{m, w}\left(q^{w}-q_{m, w}^{w}\right)+P_{m, w}^{w}\left(Q-Q_{m, w}\right)\right)\right] .
\end{aligned}
$$

Varian (1982) shows, in a unitary context, that $u^{m}\left(q_{m, w}^{m}, Q_{m, w}\right)=U_{m, w}^{m}$ and $u^{w}\left(q_{m, w}^{w}, Q_{m, w}\right)$ $=U_{m, w}^{w}(m \in M \cup\{\varnothing\}$ and $w \in W \cup\{\varnothing\})$. Using this, we can use a readily similar argument as in Varian (1982) (for the unitary consumption model) and Cherchye, De Rock and Vermeulen (2011) (for the collective consumption model) to show that the utility functions $u^{m}$ and $u^{w}$ defined above rationalize the data set $\mathcal{D}$ by a stable matching (i.e. the data solve the optimization problems underlying our stability criteria for these functions $u^{m}$ and $u^{w}$ ). 